\title{
The Breast Cancer Stem Cells Traits and Drug Resistance
}

\author{
Qinghui Zheng ${ }^{1 \dagger}$, Mengdi Zhang ${ }^{2 \dagger}$, Fangfang Zhou ${ }^{3 *}$, Long Zhang ${ }^{2 *}$ and Xuli Meng ${ }^{1 *}$ \\ ${ }^{1}$ Department of Breast Surgery, Zhejiang Provincial People's Hospital, Hangzhou, China, ${ }^{2}$ MOE Laboratory of Biosystems \\ Homeostasis and Protection and Innovation Center for Cell Signaling Network, Life Sciences Institute, Zhejiang University, \\ Hangzhou, China, ${ }^{3}$ Institutes of Biology and Medical Science, Soochow University, Suzhou, China
}

OPEN ACCESS

Edited by:

Yan Cheng,

Central South University, China

Reviewed by:

Carmela Spagnuolo,

National Research Council (CNR), Italy

Muthupandian Saravanan,

Mekelle University, Ethiopia

*Correspondence:

Long Zhang

L_Zhang@zju.edu.cn

Xuli Meng

mxlmail@126.com

Fangfang Zhou

zhoufangfang@suda.edu.cn

${ }^{\text {t}}$ These authors have contributed equally to this work

Specialty section: This article was submitted to Pharmacology of Anti-Cancer Drugs, a section of the journal

Frontiers in Pharmacology

Received: 28 August 2020

Accepted: 17 November 2020

Published: 28 January 2021

Citation:

Zheng Q, Zhang M, Zhou F, Zhang L and Meng $X$ (2021) The Breast Cancer Stem Cells Traits and Drug Resistance.

Front. Pharmacol. 11:599965.

doi: 10.3389/fphar.2020.599965
Drug resistance is a major challenge in breast cancer $(\mathrm{BC})$ treatment at present. Accumulating studies indicate that breast cancer stem cells (BCSCs) are responsible for the $\mathrm{BC}$ drugs resistance, causing relapse and metastasis in BC patients. Thus, BCSCs elimination could reverse drug resistance and improve drug efficacy to benefit BC patients. Consequently, mastering the knowledge on the proliferation, resistance mechanisms, and separation of BCSCs in BC therapy is extremely helpful for BCSCs-targeted therapeutic strategies. Herein, we summarize the principal BCSCs surface markers and signaling pathways, and list the BCSCs-related drug resistance mechanisms in chemotherapy (CT), endocrine therapy (ET), and targeted therapy (TT), and display therapeutic strategies for targeting BCSCs to reverse drug resistance in BC. Even more importantly, more attention should be paid to studies on BCSC-targeted strategies to overcome the drug resistant dilemma of clinical therapies in the future.

Keywords: breast cancer stem cells, drug resistance, clinical therapy, surface markers, breast cancer stem cell signaling pathways

\section{INTRODUCTION}

Breast cancer (BC) is one of the most common cancers diagnosed among women and ranked as the second cause of cancer-related death among women, after lung cancer (DeSantis et al., 2019; Siegel et al., 2019). There are various types of BC therapeutic strategies, such as breast surgery, radiotherapy (RT), chemotherapy (CT), endocrine therapy (ET), targeted therapy (TT), and others, which are based on the types of tumor pathologies. For example, breast-conserving/mastectomy surgery and adjuvant CT are applied to treat early BCs. Antitumor drugs are utilized alone or in combination to reduce the risk of $\mathrm{BC}$ recurrence. For ERa-positive and Her2-positive tumors patients, hormone therapy and targeted therapy, respectively, conduce to significant prognosis improvements. Additionally, chemotherapy is considered the best option in advanced triple-negative BC (TNBC). These treatment options have contributed to a $\mathrm{BC}$ death rate decline over the past three decades (DeSantis et al., 2019). Hence, therapies improvement is a milestone in BC therapy.

However, many $\mathrm{BC}$ patients still experience poor drug response and tumor recurrence in clinical observation (Harbeck and Gnant, 2017). Some BC cells exhibit intrinsic drug-resistance, while others are initially drug-sensitive, but acquire resistance to anticancer drugs (Abad et al., 2020). These drug failures are considered as chemoresistance in $\mathrm{BC}$ cells, owing to the survival of a special population of heterogeneity cells in tumors which possess drug-resistance features (Eiro et al., 2019). These heterogeneity cells are known as residual disease and can eventually lead to recurrence (Figure 1).

Cancer stem cells (CSCs), which were discovered and developed over the past decades, play a major role in drug-resistance and relapse of solid tumors (Reya et al., 2001; Clarke et al., 2006). Besides drug-resistance, previous studies have showed that cancer initiation (Barker et al., 2009), 


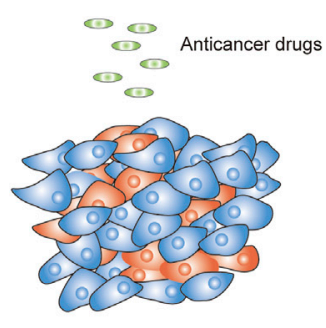

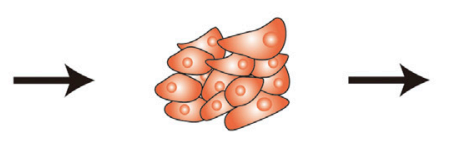

Residual disease

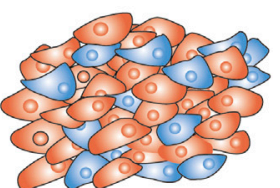

Relapsed tumour

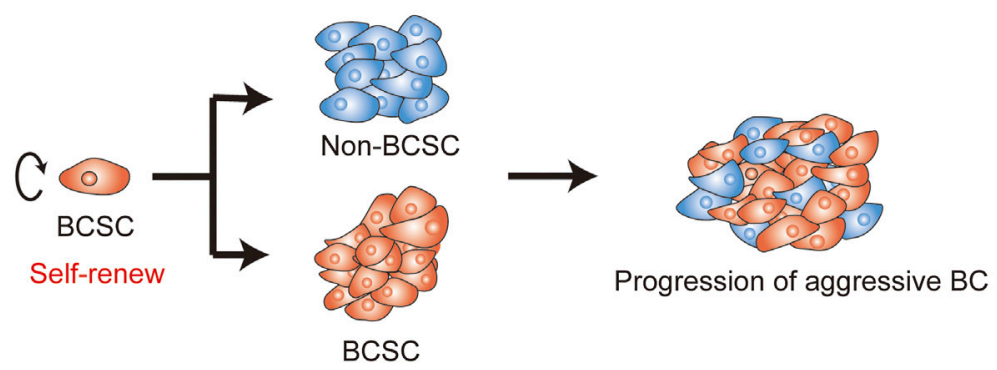

FIGURE 1 | Self-renew in BCSCs. (A) Anticancer drugs are often utilized for treat BC, efficiently targeting breast cancer cells (BCCs) (blue cells), but not BCSCs (orange cells). The residual stem-like cell populations can drive a more aggressive BC and trigger recurrence. (B) BCSCs can form a new tissue by the balance of renewal and divisions.

progression (Lytle et al., 2018), and metastasis (Oskarsson et al., 2014) could also be induced by CSCs (Nalla et al., 2019). CSCs play a similar role in BC. Al-Hajj first isolated BC stem cells (BCSCs) with specific markers (EpCAM+/CD $44^{+} / \mathrm{CD} 24^{-}$) which have the potential to lead to bulk tumors in vivo (Al-Hajj et al., 2003). Targeting BCSCs, in any hypotype of BC: luminalA, luminalB, human epithelial growth factor receptor 2 (HER2) overexpression, or TNBC, is the key therapy approach to reverse drug resistance (Dey et al., 2019). Therefore, we need to understand the role of BCSCs in drug-resistance mechanisms, which will overcome the drug-resistance problem and promote BC prognosis.

Here, first we summarize the BCSC markers and signaling pathways that are possible therapeutic targets for drug resistance. More importantly, we focus on the mechanism of resistance to specific drugs, such as anthracycline, taxane, tamoxifen, trastuzumab, among others. Lastly, novel studies about emerging therapies of reversing drug resistance by targeting BCSCs are discussed. We insist that the important breakthroughs in the field of BCSCs research will help researchers effectively find and target $\mathrm{BC}$ resistance mechanism and, ultimately, help patients achieve a favorable prognosis.

\section{CENTRAL SURFACE MARKERS IN BREAST CANCER STEM CELLS}

BCSCs surface biomarkers are utilized for identifying or isolating BC. However, emerging studies show that different surface markers determine different BCSCs (Dey et al., 2019;
Sridharan et al., 2019); the functions of BCSCs are based on the type of markers they contain. The key surface markers of BCSCs and their functions in BC are listed in Table 1. Novel drugs are being designed to target these markers for regulating the activation of BCSCs in order to achieve an efficient response to anti-BC treatment (Figure 2). Thus, we list the central surface markers in BCSCs and their known functions in BCSCs regulation.

\section{CD44}

CD44 was initially used to isolate BCSCs from tumors. Meanwhile, BC cells with an overexpression of CD44 marker, known as BC-initiating cells (BCIC), showed tumorigenic ability in vivo (Ponti et al., 2005). CD44 is a cell membrane receptor for hyaluronan acid (HA) (Bourguignon et al., 2004). HA-CD44 interaction play an important role in inhibiting metastasis (Lv et al., 2018a; Bourguignon, 2019), reversing drug resistance (Liu J. et al., 2019), and suppressing invasion (Sarkar et al., 2019) among BC cells. For instance, The binding of CD44 and HA activated c-Src-Twist/miR-10b/RhoGTPase-ROK signaling, that are associated with the activation of the PI3K/AKT-dependent invasion and metastasis in cancers (Bourguignon et al., 2010). Furthermore, the high expression of CD44 is essential for BC multidrug resistance by regulation of the chemoresistance receptor through stimulation of signal transducer and activator of transcription 3 (STAT3) pathway (Louderbough and Schroeder, 2011). Moreover, the interaction of the cleaved product of CD44 (CD44ICD) and cAMP-response element binding protein (CREB) can up-regulate fructose-2,6bisphosphatase 4 (PFKFB4) expression, which activates 
TABLE 1 | The BCSCs Surface markers in significant literatures.

Surface markers

Mediated signaling

CD44 (Al-Hajj et al., 2003) PI3K/AKT signaling (Ghatak et al., 2002)

NF- $\kappa B$ signaling (Cho et al., 2015) CREB/TGF- $\beta 2$ signaling (Ouhtit et al., 2018)

ALDH1 (Ginestier et al.,

2007)

CD133

IL6/Notch3 signaling (Sansone et al. 2016)

EpCAM

ABCG2

GD2

CXCR4
SDF-1/CXCR4 signaling (Yi et al., 2014)

\section{Function in BC}

Forming tumors (Al-Hajj et al., 2003), promoting metastasis (Hill et al., 2006), associated with (BRCA1) mutational status (Bane et al., 2013)

Predicting prognosis (Bane et al., 2013), stimulating migration (Bourguignon et al., 2003), promoting cell adhesion (Ponta et al., 2003), promoting. Cell growth, survival, and invasion (Louderbough and Schroeder, 2011)

Associated to tumor-initiating characteristics (Ginestier et al., 2007), promoting self-renewal (Ginestier et al., 2009), As target for BCSCs-targeted therapy (Angeloni et al., 2015) Predicting prognosis 11823860 (Alexe et al., 2006; van't Veer et al., 2002) promoting metastasis (Marcato et al., 2011) Regulation of ET-resistant (Sansone et al., 2016) promoting self-renewal (Sansone et al., 2016) BCSCs identification (Bai et al., 2018)

CD133 aptamers or CD133-targeted drug delivery system for BCSCs-targeted therapy (Shigdar et al., 2013; Swaminathan et al., 2013)

Regulation of migration and metastasis (Baccelli et al., 2013) promoting chemoresistance (Wang T. et al., 2015)

Promoting BC chemoresistance, tumorigenicity and metastasis (Bai et al., 2018), Sorting BCSCs from BRCA1-mutated BC cells (Leccia et al., 2014)

Aassociated with GD3S-mediated EMT (Liang et al., 2017), promoting tumorigenicity and metastasis (Battula et al., 2017),BCSCs. identification (Bai et al., 2018)

Promoting metastasis (Muller et al., 2001), promoting migration or invasion (Luker et al., 2012)

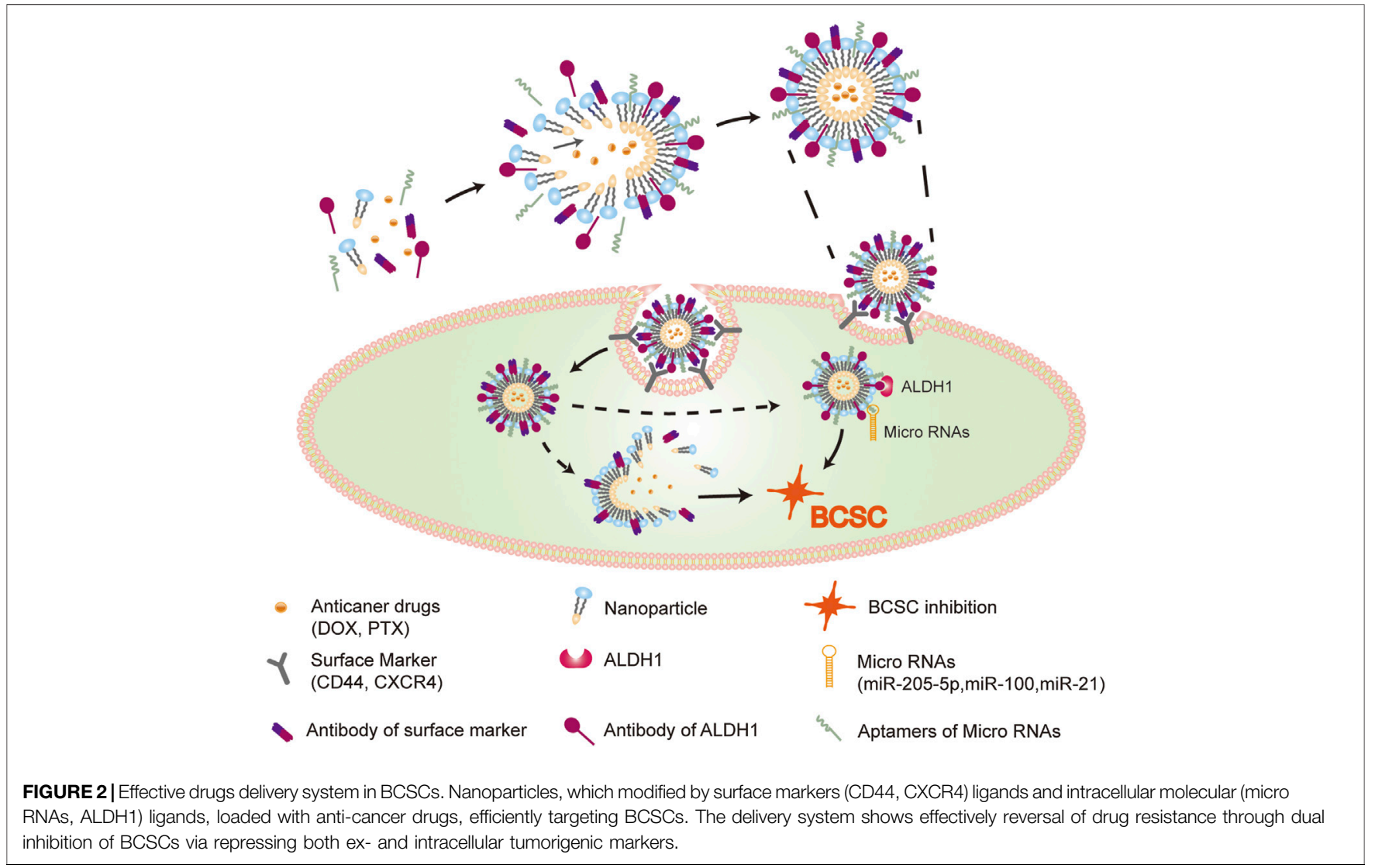

glycolysis and impoves BC stemness (Gao et al., 2018). CSCs are associated with tumor metastasis and invasion.

Conversely, CD44 is also utilized as a targeting marker of HAdrug-nanocomposite complex. The combination of HA and docetaxel (DTX), loaded in polymeric nanoparticles (NPs), improved the effect of drug delivery by targeting $\mathrm{CD} 44+^{\text {high }}$ BC cells (Gaio et al., 2020). Similarly, a HA-NPs complex loaded with paclitaxel (PTX) was well designed to target CD44 
for improvement of chemotherapeutic effects in metastatic cancer (Lv et al., 2018b). These results demonstrate the important role of CD44 in BC stemness, invasion, metastasis, and drug resistance. We should aim at significantly reversing drug resistance through the use of nano-drug combinations, improving drug efficacy, and ultimately, ensuring a favorable prognosis.

\section{CD133}

CD133, known as Prominin-1, is independently expressed on the surface of stem cells and various tissue tumor stem cells. Similar to $\mathrm{CD} 44, \mathrm{CD} 133 \mathrm{BC}$ cells show stem-like properties and are found to be enrich in basal-like, triple negative, HER2+ or luminal tumors (Borgna et al., 2012).

xenograft-initiating $\mathrm{CD} 44^{\text {pos }} \mathrm{CD} 49 \mathrm{f}^{\text {high }} \mathrm{CD} 133 / 2^{\text {high }}$ cells among ER-negative tumors were capable of forming ERnegative tumors (Meyer et al., 2010), supporting the evidence that CD133 is an identifier molecule for BCSCs with high aggressive properties.

The accumulation of CD133 $3^{\text {high }}$ BCSCs aggravated BC and tended to induce drug-resistance (Bousquet et al., 2017), proliferation (Brugnoli et al., 2017), vasculogenic mimicry (Liu et al., 2013), invasion, and metastasis (Bock et al., 2014). For instance, heterogeneous BC cells with CD133 marker displayed resistance to drugs and the potential to form a mass in NOD/ SCID mice (Wright et al., 2008). Moreover, CD133 ${ }^{\text {high }}$ BCSCs were enriched in the tumors of hormonal therapy (HT)-resistant $\mathrm{BC}$, forming metastatic luminal BC by self-renewal during HT (Sansone et al., 2016). The capability of self-renewal can be switched through re-expression of estrogen receptor (ER) by inhibition of IL6R/IL6-Notch pathways (Sansone et al., 2016). Furthermore, a ribonucleoprotein complex (LncRNA MALAT1 and HUR) down-regulated the expression of CD133+ phenotype and inhibited the stem cell properties of BCSCs, leading to tumorigenesis and metastasis failure both in MCF-7 and MDA-MB-231 (Latorre et al., 2016), revealing the indirect mechanism of CD133 and drug resistance in BC.

Recently, a novel CD133-targeting drug delivery system that uses nanoparticles loaded with drugs was reported. An antiCD133 antibody into nanoparticles loaded with paclitaxel, increased the accumulation of paclitaxel in CD133+ cells, decreased the population of BCSCs, and inhibited the tumorigenic ability in vivo (Swaminathan et al., 2013). This implies that CD133-targeting will contribute to the development of BCSC-targeting therapeutics to reverse drug resistance.

\section{EpCAM}

EpCAM, a type I transmembrane glycoprotein, is known as a phenotype of epithelial tumors and is overexpressed in BCSCs (Munz et al., 2009). EpCAM can promoting BCSCs survival through the activation of $\mathrm{Wnt} / \beta$-catenin signaling pathway (Sena and Chandel, 2012). It can also promote adhesion between epithelial cells, playing an important role in migration and metastasis. For example, $\mathrm{EpCAM}^{+}$disseminated tumor cells (DTCs), isolated from the peripheral blood of BC patients, contained a class of metastatic initiating $\mathrm{BC}$ cells that could cause bone, lung, and liver metastases in NOD-SCID mice
(Baccelli et al., 2013). Moreover, EpCAM still plays an important role in reversing resistance. For instance, Survivin silencing, mediated by EpCAM aptamer, can make BCSCs sensitive to doxorubicin, leading to the reversal of resistance, which indicates that this novel strategy is an effective method to reverse drug resistance in BC (Wang T. et al., 2015).

\section{ALDH1}

ALDH1 is an $\mathrm{NAD}(\mathrm{P})+$ dependent enzyme that mediates the oxidation of intracellular aldehydes into carboxylic acids. ALDH1 acts as a common marker of both normal and malignant breast stem cells, especially in BCSCs. ALDH1-high activity is an independent predictor of progression and poor survival of $\mathrm{BC}$ patients (Ginestier et al., 2007). Moreover, CD44+/CD24-/ ALDH1+ MDA-MB-231 and CD44+/CD133-/ALDH1+ MDA-MB-468 BC cells demonstrated stronger tumorigenic and metastatic capabilities than $\mathrm{ALDH} 1^{\text {low }} \mathrm{CD} 44^{\text {low }} \mathrm{BC}$ cells (Croker et al., 2009).

However, ALDH activity of BCSCs was mainly dependent on ALDH1A3, rather than on ALDH1A1 (Marcato et al., 2011), further enhancing the understanding of specific targets of BCSCs. The main explanation for this difference is that the expression level of ALDH1A1 in breast epithelial cells is lower than that of ALDH1A3. The strong association between LDH1A3 high expression and metastasis in $\mathrm{BC}$ patients was also reversed to confirm the importance of ALDH1A3 in BC. Contrarily, NOTCH signaling pathway increased ALDH1A1 Lys-353 deacetylation at a post-translational level through the induction of silent information regulator 2 (SIRT2) expression, promoting tumorigenesis and tumor growth in a BC model (Zhao et al., 2014). Conversely, inhibition of ALDH activity resulted in drug (doxorubicin/paclitaxel) resistance reversal in $\mathrm{ALDH}^{\text {high }} \mathrm{CD} 44^{+}$ BCSCs (Croker and Allan, 2012). Therefore, these studies reveal that ALDH1 not only can be utilized to distinguish BCSCs, but also as a potential therapeutic target for drug resistance reversal in BC. ALDH1 regulation might be useful in explaining drug resistance in further research.

\section{CXCR4}

As a specific receptor of stromal cell-derived factor-1 (SDF-1), CXC chemokine receptor 4 (CXCR4) is essential for BCSCsrelated metastasis. The SDF-1/CXCR4 signaling pathway mediates the role of promoting the directional metastasis of CXCR4+ BCSCs. Both antibody neutralization and CXCR4 knockdown inhibited the proliferation of orthotopically transplanted breast tumor and metastasis (Muller et al., 2001). Non-metastatic BCSCs promote the transformation of nonBCSCs to CXCR4 ${ }^{+}$BCSCs in BC tissues (Mukherjee et al., 2016). Besides, CXCR4+ BCSCs displayed decreased vimentin and increased E-cadherin, indicating the occurrence of epithelialmesenchymal transitions (EMT). These findings demonstrate that $\mathrm{CXCR}^{+}$BCSC triggered EMT-related metastasis.

$\mathrm{BC}$ metastasis is closely related to drug resistance, so CXCR4 may be a key factor of reversins drug resistance. CXCR4 is also closely related with tumor microenvironmental changes. CXCR4 is highly expressed in BC metastases; thus, I.X. found that suppressed CXCL12/CXCR4 signaling pathway or silenced 
CXCR4 in BCSCs sensitizes BC to immune checkpoint blockers, inhibiting metastasis reversing drug-resistance in BC (Chen I. X. et al., 2019). In a similar mechanism, DPP-4 inhibitors were found to reverse drug-resistance via $\mathrm{ABC}$ transporters-mediated CXCL12/CXCR4/mTOR/TGF $\beta$ axis in BC cells (Li et al., 2020). An innovative strategy, consisting of an oncolytic virus loaded with a CXCR4 antagonist, was utilized for targeting the CXCL12/ CXCR4 signaling pathway, being remarkably effective in primary and metastatic BC (Gil et al., 2013). Furthermore, the activation of SDF-1/CXCR4 signaling pathway can increase the phosphorylation of 60 proteins with migration or invasion properties in $\mathrm{BC}$, which might be key mediators for CXCR4induced BCSCs proliferation (Yi et al., 2014). These evidences emphasized CXCR4 as a therapeutic target to inhibit microenvironment-induced stemness and the appearance of metastatic phenotypes and made it possible to eradicate the activation of CXCR4-related signaling pathway, decreasing the proportion of CXCR4+ BCSCs.

\section{ABCG2}

As a known drug-resistant protein, ABCG2 is highly expressed in BC resistant cells, especially in resistance-related BCSCs. Sun found that stem-like $\mathrm{CD} 44^{+} \mathrm{CD} 24^{-/ \text {low }}$ cells isolated from several BC cell lines, such as SK-BR-3, MDA-MB-231, and MCF-7 displayed a higher expression of ABCG2 than non-stem cells (Sun et al., 2015). Furthermore, ABCG2 is considered to be a more effective surface marker for BCSCs identification than $\mathrm{CD}_{4} 4^{+} \mathrm{CD} 24^{-}$(Leccia et al., 2014). Moreover, several pieces of evidence have highlighted ABCG2 as a therapeutic target to overcome $\mathrm{BC}$ multidrug resistance. For instance, downregulation of either Rab5A or Rab21 increases surface expression of ABCG2 and efflux of intracellular drugs, reversing BC drug-resistance (Yousaf and Ali, 2020). Moreover, it has also been demonstrated that drug resistance can be reversed by ABCG2 modulators at a molecular level (Hasanabady and Kalalinia, 2016; Pena-Solorzano et al., 2017). However, few small molecule modulators have shown to be effective in preclinical trials. Therefore, the role of ABCG2 inhibitors in reversing resistance by mediating BCSCs should be re-examined and more in vivo evidence should be presented.

\section{GD2}

$\mathrm{GD} 2$, a b-series ganglioside, is another cell membrane phenotype of BCSCs. Indeed, GD2 ${ }^{+} \mathrm{BC}$ cells, isolated from either $\mathrm{BC}$ cell lines or clinical tumor tissue in BC patients, show stemness. Meanwhile, it has been revealed that GD2+ cells, human mammary epithelial cells-derived GD2+ cells, were highly $\mathrm{CD} 44^{+} \mathrm{CD} 24^{-}$(Battula et al., 2012). GD3 synthase, a ratelimiting enzyme, regulates the synthesis of GD2 and is considered a kind of therapeutic target for BCSCs. GD3S was positively correlated with the expression of GD2+ in BCSCs, and the low expression of GD3S not only resulted in the decreased expression of GD2+, but also disrupted EMT-mediated tumor formation ability of BC cells (Liang et al., 2017). Consistently, another study indicated that the high expression of GD3S was closely associated with the activation of nuclear factor kappa-B $(\mathrm{NF}-\kappa \mathrm{B})$ in $\mathrm{GD}^{+}$BCSCs. The Inhibition of NF- $\kappa \mathrm{B}$ signal can significantly reduce the expression of GD3S and the proportion of $\mathrm{GD}^{+}{ }^{+}$BCSCs, abolishing the capability of BCSCs to metastasize (Battula et al., 2017). Based on the correlation between BCSCs, GD3S, and GD2, the development of GD3S-related signals as a novel therapeutic target may induce BCSCs to reverse drug resistance.

\section{CENTRAL SIGNALING PATHWAYS IN BREAST CANCER STEM CELLS}

As mentioned above, surface markers play an important role in maintaining the stemness of BCSCs, but they can't work independently of intercellular signaling pathways. Here, we continue to describe the activation of several key intracellular signaling pathways in $\mathrm{BC}$, as a result of gene mutation, epigenetic modifications, or tumor microenvironment changes, which generate drug resistance-related BCSCs. Therefore, understanding the relevant pathways can contribute to better understand the characteristics of BCSCs and determine the research direction of reversing drug resistance targeted therapy. Major mechanisms of drug resistance in BCSCs are shown in Figure 3

\section{Notch Signaling Pathway}

Notch signaling pathway is one of the regulative mechanisms of BCSCs' self-renewal and survival. Cytokine IL-6 regulates Notch signaling, and the increase of IL- 6 was detected in BC treated with HT, activating the Notch 3 signaling in BC cells. The activation of Notch3 signaling enables BC cells to self-renew instead of the ERdependent survival mechanism, thus impacting clinical efficacy of HT. However, inhibiting Notch signaling significantly reduced the self-renewal ability of CD133 ${ }^{\text {high }} \mathrm{ER}^{\text {low }}$ BCSCs in HT-resistant cells (Sansone et al., 2016). Similarly, another study indicated that the combination of MK-0752 (gamma secretase inhibitors) and Tocilizumab (IL6R antagonist) remarkably decreases the proportion of BCSCs and inhibits cell proliferation or tumor growth in BC, through Notch3 signaling pathway (Wang D. et al., 2018).

Moreover, emerging evidence suggested that BCSCs mediate drug resistance in $\mathrm{BC}$ through Notch-related signaling pathway. For example, the activation of Notch signaling pathway promotes the appearance of stem cell phenotype in $\mathrm{ERa} / \mathrm{ESR} 1^{+} \mathrm{BC}$ cell lines and causes drug resistance to ET for BC (Gelsomino et al., 2018). Consistently, the activation of JAG1-NOTCH4 signaling pathway stimulates BCSCs activity and generates anti-estrogen resistance in BC (Simoes et al., 2015). In particular, Notch1 also mediated trastuzumab resistance in BCSCs by inhibiting PTEN expression to cause the activation of ERK1/2 signaling. Notch1-PTENERK1/2 signaling might be a target for the novel therapy strategies of combining anti-Notch1 and anti-MEK/ERK to reverse trastuzumab resistance (Baker et al., 2018).

\section{Wnt $/ \beta$-Catenin Signaling Pathway}

$\mathrm{Wnt} / \beta$-catenin signaling pathway also plays an important role in BCSCs self-renewal. A previous study has shown that Wnt/ $\beta$-catenin signaling pathway was deemed as a key mechanism 


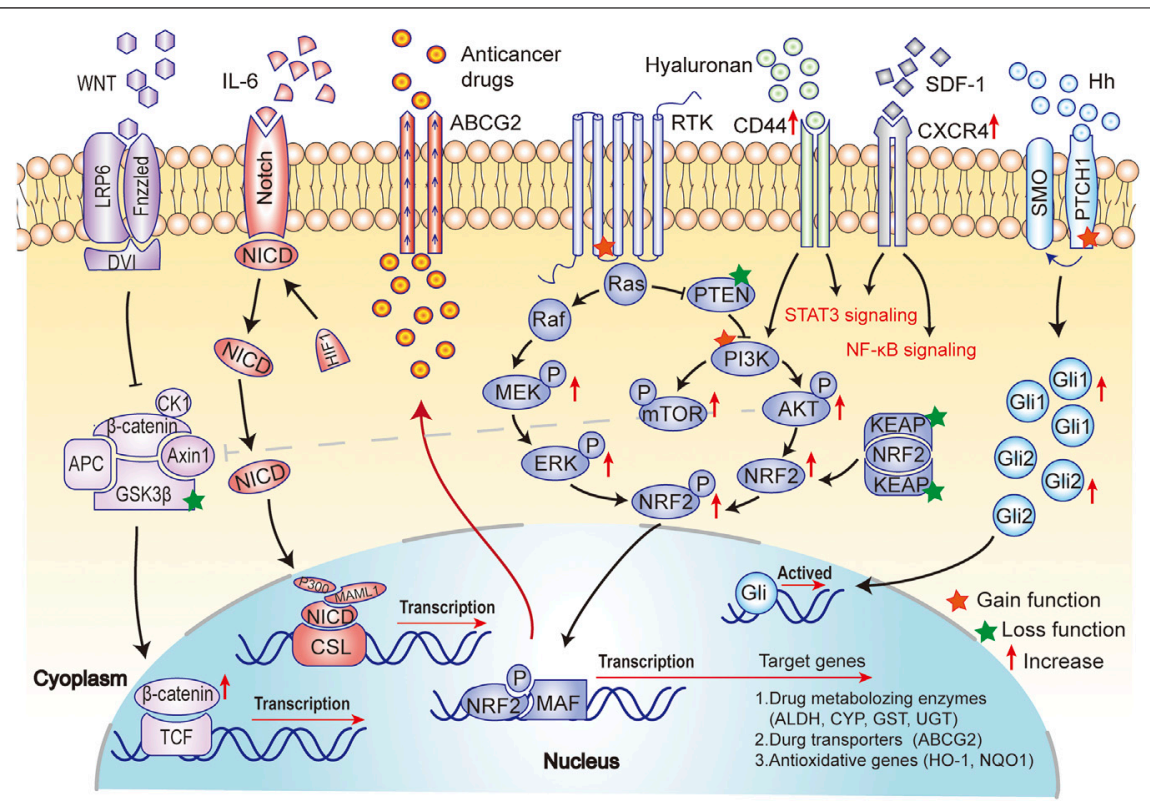

FIGURE 3 | Major mechanisms of drug resistance in BCSCs. Drug resistance is not only a result of the activation of the self-renewal (Notch and Hh signaling pathway) and anti-apoptotic (PI3K/AKT/mTOR signaling) in BCSCs, but also a consequence of the promotion of metastasis (EMT and Wnt/ $\beta$-catenin signaling pathway), anti-oxidative activity (NRF2 signaling) and ATP-binding cassette (ABC) transporter (ABCG2) activity in BCSCs.

of Sam68- mediated self-renewal in BC cells (Wang L. et al., 2015). Another study displayed that Gomisin M2 remarkably inhibited BCSCs self-renewal by suppressing the Wnt/ $\beta$-catenin signaling pathway (Yang Y. et al., 2019). Compared to other cells, the higher level of $\mathrm{Wnt} / \beta$-catenin signaling pathway contributes to the high resistance level of BCSC. CWP232228, a smallmolecule of $\mathrm{Wnt} / \beta$-Catenin inhibitor, suppressed the proliferation of BCSCs by inhibiting $\beta$-catenin-mediated transcription (Jang et al., 2015). Furthermore, this result implied that $\mathrm{Wnt} / \beta$-catenin might indirectly regulate drug resistance by BCSCs self-renewal or proliferation, promoting $\mathrm{Wnt} / \beta$-catenin as a therapeutic target for BCSCs therapy in the future.

\section{PI3K/AKT/mTOR Signaling Pathway}

The activation of the phosphatidylinositol 3-kinase (PI3K)related signaling pathway in BCSCs was reported in recent years and can be contribute to drug resistance in BC. Mounting evidence demonstrated that PI3K/AKT/mTOR signaling pathway has an important role on ET-resistance in ER+ BC (Droog et al., 2013; Ojo et al., 2015). PI3K/Akt/mTOR signaling pathway induces BCSCs metastasis by CD44 regulation. Moreover, the interaction of $\mathrm{PI} 3 \mathrm{k}$ and $\mathrm{Wnt} / \beta$-catenin signaling maintain the self-renewal and stemness abilities of BCSCs (Solzak et al., 2017).

Impressively, inhibition of $\mathrm{PI} 3 \mathrm{~K} / \mathrm{AKT} / \mathrm{mTOR}$ signaling pathway reduces BCSC survival and self-renewal. In other words, the inhibitors of $\mathrm{PI} 3 \mathrm{~K} / \mathrm{AKT} / \mathrm{mTOR}$ signaling pathway impact the activity of BCSCs. For instance, IGF-1R, a stemness marker, is associated with $\mathrm{BC}$ disease progression. Inhibitors of IGF-1R and its downstream PI3K/Akt/mTOR signaling pathway reduced the population of BCSCs. Therefore, IGF-1R/PI3K/Akt/ mTOR signaling pathways are favorable targets for the treatment of BCSCs (Chang et al., 2013). Indeed, rapalogs, such as NVPBEZ235 and NVPBGT226, were utilized as inhibitors of both PI3K and mTOR. Meanwhile, the inhibition of PI3K by rapalogs could stimulate GLP1-mediated stem-like features in BC cell lines, as the BCSCs generated imply rapalogs resistance in $\mathrm{BC}$ (Posada et al., 2017). Hence, future research is necessary to elucidate the relationship between the distinct mechanisms of drug resistance and the regulation of PI3k-mediated BCSCs.

\section{Hedgehog Signaling Pathway}

The activation of Hh signaling pathway is essential to balance tissue homeostasis and self-renewal in BC. Generally, Hh signaling pathway is up-regulated in BCSCs, which may be involved in stemness maintenance. However, there are few pieces of evidence to understand the abnormal activation of Hh signaling pathway in BCSCs. Interestingly, $\mathrm{SHH}$ (Sonic Hedgehog), secreted by BCSCs, regulated cancer-associated fibroblasts (CAFs) via the activation of Hh signaling (Valenti et al., 2017), promoting BCSCs proliferation and self-renewal. Furthermore, Shh (Sonic Hedgehog)-mediated Hh signaling activation gives rise to salinomycin resistance (He et al., 2015). Conversely, inhibition of the $\mathrm{Hh}$ signaling pathway could sensitize BCSCs to paclitaxel by cyclopamine (He et al., 2015). So far, rare inhibitors of Hh signaling pathway were applied to regulate BCSCs. Thus, further studies on the activation mechanisms of $\mathrm{Hh}$ signaling pathway-related stemness maintenance or resistance in BCSCs are needed to identify drugs that target $\mathrm{Hh}$ signaling pathway for reversing drug resistance. 


\section{RESISTANCE TO CANCER THERAPY}

\section{Resistance to Chemotherapy}

Chemotherapy is an important part of BC routine treatment. Effective neoadjuvant chemotherapy helps patients to reduce tumor burden and clinical stage and provides opportunities for breast conserving surgery. Moreover, accumulating evidence indicated that advance $\mathrm{BC}$ patients benefit from chemotherapy. However, recent studies showed that the phenomenon of BCSCs enrichment occurs after chemotherapy in BC. Therefore, we focus on various chemotherapeutic drugs, listing the specific relationship between BCSCs and drugs, understanding the mechanism of chemotherapy resistance and summarizing the potential therapeutic strategies to reverse drug resistance.

\section{Paclitaxel Resistance}

Paclitaxel, a microtubule stabilizer, is widely used in BC clinical chemotherapy. It can keep the cells in the G2/M phase to inhibit the cell cycle (Horwitz et al., 1986). Unfortunately, paclitaxel resistance is becoming a clinical challenge in $\mathrm{BC}$ treatment. The mechanisms of paclitaxel resistance are the following. First, paclitaxel-resistant cells have the mutant microtubule binding sites, which can impact tubulin expression. Mutations in microtubule-related proteins (e.g., $\beta I-t u b u l i n ~(G i a n n a k a k o u$ et al., 1997) and ßIII-tubulin (Magnani et al., 2006)) contributed to paclitaxel resistance. Secondly, the expression of transporters, such as ATP-binding cassette transporter MDR-1/ P-gp (ABCB1) (Genovese et al., 2017), BCRP (ABCG2) (Arnason and Harkness, 2015; Robey et al., 2018), which are required for paclitaxel resistance, is abnormal. Paclitaxel-resistant cells exhibit stem-like properties (Bumbaca and Li, 2018). Some scholars insist that tumor stem cells can resist to chemotherapy, and that a higher expression of CD44+/CD24- tumors displayed greater resistance to neoadjuvant chemotherapy (Creighton et al., 2009; Marotta et al., 2011). Recently, Tanei found that ALDH1 is enriched in chemotherapy resistance cells (Tanei et al., 2009). Interestingly, ALDH1 and CD44 were utilized as important surface markers to isolate BCSCs.

Recently, with the going research between BCSCs and paclitaxel resistance, scientists often focus on the biological metabolism of BCSCs with a unique perspective. Lee discovered that the interaction of MYC and MCL1 regulated the production of reactive oxygen species (ROS) and participated in mitochondrial oxidative phosphorylation (OXPHOS), further activating the HIF-dependent hypoxia pathway and enhancing the enrichment of BCSCs and paclitaxel resistance (Lee et al., 2017). Similarly, the laboratory of Dr. Samanta investigated and verified that, after paclitaxel or gemcitabine chemotherapy, BCSCs increased activity and expression of HIF-1 $\alpha$ and HIF$2 \alpha$ through the paclitaxel-ROS-HIF-IL-6/IL-8 axis after chemotherapy (paclitaxel or gemcitabine) (Samanta et al., 2014). Consequently, HIF-mediated downstream signaling pathways will become a crucial target for paclitaxel resistance in BCSCs. Ultimately, IL-6 and IL-8, paclitaxel-induced, increased BCSCs enrichment and drug resistance through the STAT3 (Marotta et al., 2011) and TGF- $\beta$ pathways (Bhola et al.,
2013), respectively. Thus, the intrinsic relationship between STAT3 signaling and TGF- $\beta$ pathway can also be an important target to regulate BCSCs to reverse drug resistance. In summary, paclitaxel resistance is not only related to its unique metabolic pathway, but also to the biological behavior of BCSCs.

\section{Anthracyclines Resistance}

Anthracyclines, inhibitors of topoisomerase II (TOPO II), are a broad-spectrum chemotherapy drugs, including doxorubicin and epirubicin, which are widely used in BC chemotherapy. Nevertheless, the emergence of drug resistance often caused the failure of anthracyclines chemotherapy. Emerging studies have shown that anthracyclines could exhibit different drug resistance patterns in different parts of cells (Capeloa et al., 2020): on the cell envelope, ATP-binding cassette transporter can decrease the concentration of intracellular anthracyclines (Gottesman et al., 2002; Sun et al., 2015). In the cytoplasm, alterations in apoptosis (Gyorffy et al., 2005) and autophagy (Liu et al., 2011; Sun et al., 2011) pathways impact the cytotoxic effects of anthracyclines in the cytoplasm; in the nucleus, gene mutations regulate the expression and activation of TOPO II, inhibiting the effect of anthracyclines-induced DNA damage and promoting anthracyclines resistance (Press et al., 2011; Wijdeven et al., 2015). These resistance-related proteins or pathways above are affected by metabolism. Thus, anthracyclines metabolism impacts the sensitivity of BC to anthracyclines. Many CD $44^{+}$ or CD133+ BCSCs are enriched in tumors under anthracyclines therapy in BC (Jia et al., 2016). Other studies have shown that BCSCs could effectively remove DNA damage caused by chemotherapeutic drugs (Nicolay et al., 2016), and that the dysregulation of Annexin A3 (ANXA3) changed the sensitivity of BCSCs to doxorubicin (Du et al., 2018). These evidences support the role of BCSCs in anthracyclines resistance, and further studies on the therapeutic targets of BCSCs to reverse anthracyclines resistance should be performed.

\section{Platinum Resistance}

Platinum is one of the most common drugs for advanced BC because of its DNA-damaging properties. It interacts with DNA at guanine and adenine nucleotides to form Pt-DNA nonfunctional adducts that destroy double-stranded the DNA template and inhibit the division of tumor cells. However, platinum is not considered an option if progression of disease occurs during platinum-based chemotherapy. Unfortunately, only $47 \%$ of advanced BC patients are sensitive to platinum drugs (Sledge et al., 1988). Fortunately, mounting studies show that platinum resistance is associated with BCSCs. For instance, Disulfiram could improve the cytotoxic effect of cisplatin by reversing BCSCs-mediated cisplatin resistance. Meanwhile, Disulfiram exhibited difference ability to eliminate ROS between BCSCs and non-BCSCs (Yang Z. et al., 2019). Coincidentally, more than one researcher suggested that the stem-like BC cells are modulated by ROS (Nguyen et al., 2020; Nourbakhsh et al., 2020). These results implied that ROS could affect platinum resistance by regulating BCSCs. Besides, $\mathrm{Xu}$ proposed that IL-6 enhances resistance to cisplatin via the activation of STAT3 pathway in BC (Xu et al., 2018). 
Although STAT3 has been shown to induce BCSCs, it is unclear that IL6/STAT3 signaling pathway may affect the resistance to platinum by BCSCs modulation.

\section{Capecitabine Resistance}

Capecitabine is commonly used as a chemotherapy drug for advanced second-line BC. The cytotoxic effect of capecitabine is triggered by 5 -furan and thymidine phosphorylase. Therefore, low activity of thymidine phosphorylase led to capecitabine resistance in tumor tissues (Ishikawa et al., 1998). However, few pieces of evidence indicated the relationship between BCSCs and capecitabine resistance as the consequence of capecitabine metabolism complexity.

Based on clinical observations, multidrug resistance is the main form of chemotherapy resistance. For example, paclitaxelresistant $\mathrm{BC}$ often shows resistance to anthracycline at the same time (Lee et al., 2006). The main reason is that ATP-binding box transporters take part in both paclitaxel and anthracycline metabolisms, increasing the expression of drug-resistant proteins, such as MDR-1 (Genovese et al., 2017). Meanwhile, studies found that BCSCs that have DNA mismatch repair function ability, caused resistance to both anthracycline and platinum chemotherapy, but failed to resist to paclitaxel (Fedier et al., 2001). In brief, multiple pathways in BCSCs regulated the activation of metabolism and induced resistance to multiple chemotherapeutic drugs in BC, such as paclitaxel, anthracyclines, platinum, and capecitabine. Thus, it is expected that highly effective drugs targeting BCSCs emerge as a new therapeutic strategy for multi-chemotherapeutic resistance.

\section{Resistance to Endocrine Therapy}

Endocrine therapy (ET) is a highly effective treatment for estrogen receptor (ER) positive $\mathrm{BC}$ by blocking ER pathway and depriving the tumor of estrogen (Howell, 2008). As a matter of fact, the ER signaling pathway is a complicated biological pathway that regulates many functions, such as cell proliferation, invasion, and angiogenesis, and is used as a crucial survival pathway by BC cells (Manavathi et al., 2013). Different endocrine therapies work by various mechanisms, which can be divided into three different categories: selective estrogen receptor modulators (SERMs), aromatase inhibitors (AI), and CDK4/6 inhibitors. Currently, evidence continues to show that BCSCs are responsible for tumor evolution and play a crucial role in achieving ET resistance (Dey et al., 2019; Rodriguez et al., 2019).

\section{Tamoxifen Resistance}

Tamoxifen is one of the most famous selective ER modulators, which can antagonize the effects of estrogen and bind in the ER pathway to some particular target genes (Frasor et al., 2004). Thereby, adjustment of each element or transcription in ER pathway can mediate resistance to endocrine treatment by modulating ER activity or by acting as an escape pathway. Primitively, the increase of BCSCs in advanced BC indicated their potential role in tumorigenesis and tamoxifen resistance (Pece et al., 2010). Further, recent studies demonstrated that tamoxifen resistant MCF-7 (TAM-R) cells contained a higher proportion of BCSCs than non-resistant cells (Wang et al., 2012).
Therefore, we speculate that BCSCs may play an important role in endocrine resistance, and accumulating studies have confirmed this.

Recent studies provide more direct evidence on BCSCs participating in tamoxifen resistance through some important pathways. The ER signaling pathway functions as a major mechanism responsible for tamoxifen resistance. The expression of ER splicing variants, such as the estrogen related receptors and the identified short variant ERa36, have also contributed to a poor tamoxifen response (Zhang and Wang, 2013). Although considered ERa negative, BCSCs can still be stimulated by estradiol via paracrine mechanisms. A study also showed that ERa could mediate the rapid estrogen signaling in BCSCs and enhance transcription of genes related to stem cells (Gelsomino et al., 2018). ER could also promote the development of BCSCs via a crosstalk with Sox2 (Zhang Y. et al., 2012). In return, Sox 2 could promote the non-genomic estrogenstimulated activity of ER, thus inducing ER phosphorylation at Ser118 site (Zhang Y. et al., 2012; Vazquez-Martin et al., 2013). In fact, phosphorylation, ubiquitination, and other posttranslational modifications of ER and its co-regulators affect the sensitivity to different endocrine therapies (Musgrove and Sutherland, 2009). However, the role of estrogen receptors $\beta$ $(\mathrm{ER} \beta)$ in BCSCs is still partly unclear, requiring further experiments to explore its relationship with endocrine resistance and BCSCs.

Another important category of pathways involved in endocrine resistance is the growth factor family. Up-regulation of EGFR, HER2, FGFR, and IGF1 receptors (IGF1R) could activate the downstream signaling pathway, especially PI3K pathways, causing tamoxifen resistance (Chakraborty et al., 2010; Arpino et al., 2008). Lately, using gene expression analysis, it was revealed that the activation of the PI3K/AKT/ mTOR pathway and the inactivation of the PTEN tumor suppressor were the major alterations in MCF7 cell-derived BCSCs-enriched cells, compared to non-enriched cells. Downregulation of $\mathrm{PI} 3 \mathrm{~K}, \mathrm{AKT} 1$ and $\mathrm{PI} 3 \mathrm{~K} / \mathrm{mTOR}$ reduced the selfrenewal and survival of BCSCs in vitro and their tumor initiation and self-renewal ability in vivo (Gargini et al., 2015). In general, these data suggest that some regulators, such as IGF1R and PI3K, may be potential targets to recover the resistance to tamoxifen by restraining BCSCs survival and activity.

Alterations in genes involved in stemness-related pathways, such as Wnt/ $\beta$-catenin, Notch, and Sonic Hedgehog, have been proven highly effective in acquiring tamoxifen resistance. According to recent studies, activation of Wnt and Notch signaling pathways induced tamoxifen resistance and promoted BCSCs activity in MCF-7 (TAM-R) cells, while inhibition of these pathways abolished the resistance (Magnifico et al., 2009; Loh et al., 2013; Lombardo et al., 2014), supporting the important role of BCSCs in endocrineindependent and TAM-resistant proliferation. Furthermore, clinical data demonstrated that upregulation of the $\mathrm{HH}$ signaling was related with a reduction in overall survival and recurrence-free survival in estrogen receptor positive $\mathrm{BC}$ patients, even leading to tamoxife resistance (Ramaswamy et al., 2012). By contrast, the stem cell-like population, cell migration, and 
invasion declined greatly by the inhibition of the $\mathrm{HH}$ signaling, thus preventing the progress of tamoxifen resistance (Ramaswamy et al., 2012). Collectively, accumulating evidence reveals complicated mechanisms with overlapping networks of tamoxifen resistance, which partly results from BCSCs-induced evolution, regulated by Notch, Wnt/ $\beta$-catenin, $\mathrm{HH}$, and other crucial signaling pathways.

\section{Fulvestrant Resistance}

Fulvestrant, a new kind of ER downregulator, can effectively reduce the level of ER in BC cells (Dowsett et al., 2005). Actually, fulvestrant was identified as an effective antagonist to endocrinesensitive BC after failure of previous tamoxifen or aromatase inhibitor therapies (Howell and Robertson, 1995). Although the detailed mechanisms of fulvestrant resistance remain unclear, some pathways, including EGFR/ErbB2, MEK/ERK, NF-kB, PI3K-AKT, and $\beta$-catenin, have been associated with development of fulvestrant resistance (McClelland et al., 2001; Gu et al., 2002; Fan et al., 2006). It is interesting that these proteins and pathways are also correlated with the induction and maintenance of BCSCs (Hardt et al., 2012; Harrison et al., 2013; Luo et al., 2015; Majumder et al., 2016). Therefore, we speculate that BCSCs may mediate fulvestrant resistance through these pathways, but further evidence is needed to prove this.

Studies showed that resistance was associated with $G$ proteincoupled estrogen receptor-1 (GPER) and CDK6 overexpression (Giessrigl et al., 2013; Alves et al., 2016). GPER, mediating estrogen-induced proliferation breast epithelial cells, is also essential for the survival of BCSCs (Chan et al., 2020). Recently, a study showed that microRNA-221 contributed to fulvestrant resistance via activation of $\beta$-catenin in $\mathrm{BC}$ and promoted the generation of BCSCs, stimulating the production of an invasive phenotype that predicts adverse outcomes (Roscigno et al., 2016). Unfortunately, few studies on fulvestrant resistance have been reported; however, the relationship between fulvestrant resistance and BCSCs may become clearer with future research.

\section{Aromatase Inhibitors Resistance}

Aromatase inhibitors (AIs) can inactivate aromatase, block aromatase reaction, inhibit estrogen production, and reduce estrogen levels in the blood, being an ideal ET drugs for ER+ $\mathrm{BC}$ in postmenopausal women. Three AIs, such as exemestane, letrozole, and anastrozole, exhibited similar resistance mechanisms in ET (Francis et al., 2015). Besides, AIs could modulate the action of androgen through the androgen receptor (AR) as well, thereby inhibiting estrogen-dependent BC growth (Macedo et al., 2006; Takagi et al., 2010). The application of AIs greatly reduced the risk of $\mathrm{BC}$ recurrence among postmenopausal women (Magnani et al., 2013). However, AIs resistance inevitably reduces clinical benefits. Multiple mechanisms contribute to AI resistance, involving either estrogen-independent ER growth or ER-independent activation. Among these, the PI3K pathway is a significant therapeutic target. A previous study revealed that these BCSCs showed low ER expression and the activation of PI3K signaling pathway (Hardt et al., 2012), both of which eventually led to AIs resistance (Marsden et al., 2009). Actually, the alpha-specific PI3K inhibitors, such as buparlisib, alpelisib, and taselisib, were currently utilized as novel drugs for AIs-resistant BC in phase III clinical trials (NCT02437318, NTC01610284, NCT02340221).

Stromal cells, extra-cellular matrix (ECM), and other microenvironment conditions (such as hypoxia and acidity) are also responsible for the generation of BCSCs phenotypes and endocrine (AI and TAM) resistance (Generali et al., 2006; Semenza, 2015). A lot of soluble factors that promote tumor growth and vascularization, such as transforming growth factor- $\beta$ (TGF $\beta$ ), which induces epithelial-to-mesenchymal transition (EMT), are secreted by cancer-associated fibroblasts (CAFs). Furthermore, downstream signaling pathways, especially PI3K and MAPK pathways, are activated by EGFR and CXCR4, thus inducing endocrine resistance (Loh et al., 2013; Ma et al., 2015). Additionally, CXCR4 was found to enhance BCSCs self-renewal by the activation of PI3K/AKT and MAPK pathways and promoted tumorigenesis through hydrocarbon receptor (AhR) signaling (Dubrovska et al., 2012). Mesenchymal stem cells (MSCs) protected cancer cells from hormone treatment through direct cell interaction and by secreted proteins (Rhodes et al., 2010). In conclusion, the tumor microenvironment is frequently linked to endocrine resistance, partly due to self-renew and maintenance of BCSCs.

\section{Resistance to Targeted Therapy}

HER2 is a receptor tyrosine kinase which is over-expressed or genetically amplified in 15-25\% of invasive BCs. As we have seen, anti-HER2 drugs, such as trastuzumab and lapatinib, have obviously improved clinical outcomes in HER2-positive BC patients. Yet the emergence of resistance to anti-HER2 drugs becomes a main barrier during the treatment of HER2-positive BC. In order to improve the prognosis of HER2-positive BC patients, it is essential to study the mechanisms of resistance to anti-HER2 therapy (Chihara et al., 2017). Several observations suggested that the resistance to anti-HER2 drugs may be driven by CSCs (BCSCs) (Martin-Castillo et al., 2013; Seo et al., 2016). Therefore, we would like to find out how BCSCs participate in resistance to anti-HER2 drugs in HER2-positive BC.

\section{Trastuzumab Resistance}

Trastuzumab is a molecular targeting drug for HER2 tyrosine kinase receptor. The application of trastuzumab has dramatic therapeutic efficacy in HER2+ BC, but the emergence of drug resistance hinders its clinical benefits. Multiple evidence shows that the mutation of PI3KCA (Berns et al., 2007; Dave et al., 2011) and loss of PTEN (Nagata et al., 2004; Koninki et al., 2010; Gallardo et al., 2012) leads to trastuzumab resistance in BC. Indeed, trastuzumab resistance was also associated with CSCs. CSCs may induce drug resistance via the activation of PI3K/AKT, JAK/STAT3 and NF-kB pathways (Wang et al., 2017). Meanwhile, PTEN loss and PI3KCA mutation could lead to abnormal activation of the downstream PI3K/Akt/mTOR pathway, which in turn, regulates BCSCs pool (Dey et al., 2019). Similarly, PTEN down-regulation increased BCSCs population through Akt activation of Wnt signaling pathway 
(Korkaya et al., 2012). We can speculate that the loss of PTEN and the mutation of PI3KCA lead to the activation of downstream $\mathrm{PI} 3 \mathrm{~K} / \mathrm{Akt} / \mathrm{mTOR}$ pathway in BCSCs, which results in trastuzumab resistance. Another mechanism of trastuzumab resistance was the activation of IL-6 inflammatory loop mediated BCSCs expansion, resulting in drug resistance of BC to trastuzumab. Meanwhile, IL-6 was found to inhibit PTEN when activating Akt, STAT3, and NF-kB pathways (Korkaya et al., 2012). Interestingly, STAT3 activation led to an increase in stem cell properties, which caused over-expression of HER2 and trastuzumab resistance (Chung et al., 2014). Thus, targeting upstream of JAK/STAT3 pathway, for instance IL-6 receptor antibody, could inhibit trastuzumab resistance and reduce the CSC population. A previous study showed that an excellent functional biomarker for trastuzumab resistance is Mucin1 (MUC1), and its cleaved form is named $\mathrm{MUCl}^{*}$ (Sand et al., 2020). Interestingly, anti-MUC1* was found to have a dramatic, stimulatory effect on stem cell growth (Hikita et al., 2008). Fessler demonstrated a significant increase in the number of $\mathrm{MUCl}^{\star}$ in trastuzumb resistant cell lines (Fessler et al., 2009). In conclusion, $\mathrm{MUC1}^{*}$ may be a target for reversing drug resistance of trastuzumab. Among these mechanisms, it is not difficult to find that CSCs are critical in trastuzumab resistance. Thus, the BCSCs-targeted strategy may be worth further research in recovering sensitivity of trastuzumab in $\mathrm{BC}$, and may bring benefits to patients at risk of $\mathrm{BC}$ recurrence.

\section{Lapatinib Resistance}

Lapatinib is an oral small molecule drug, which targets both epidermal growth factor receptor (EGFR) and human epidermal growth factor receptor 2 (HER2). Its resistance involves many factors, such as the pathways of receptor tyrosine kinase, nonreceptor tyrosine kinase, CSCs, microRNA, tumor metabolism, among others (Shi et al., 2016). MiR-205-5p is a highly conserved miRNA involved in cell differentiation, migration, and proliferation, which was found to be highly expressed in BCSCs. Moreover, it leads to lapatinib resistance by directly repressing HER2 and indirectly inhibiting EGFR (De Cola et al., 2015; Xiao et al., 2019). It was speculated that the lapatinib resistance caused by miR-205 was via the activation of PI3K/ AKT signaling pathway. Therefore, down-regulating the expression of miR-205-5p contributed to inhibit the lapatinib resistance in BCSCs. The other resistance mechanism for lapatinib was associated with $\mathrm{CD} 44+/ \mathrm{CD} 24-$, which are surface markers of CSCs (Dey et al., 2019). Knocking down CD24 could not only increase the sensitivity of HER2-positive BC cells to lapatinib, but also inhibit Akt phosphorylation (Hosonaga et al., 2014). For this reason, CD24 may be a target to reverse lapatinib resistance in BC. Actually, the use of lapatinib greatly improves BC prognosis. Nevertheless, clinical evidence suggested that lapatinib resistance led to poor therapeutic efficacy in HER2-positive BC patients. As described in the above mechanisms, CSCs seem to be the key to solve lapatinib resistance. Consequently, further understanding of the regulatory mechanisms of CSCs in lapatinib resistance in $\mathrm{BC}$ is essential for developing targeting strategies.
Here, we summarize the resistance mechanism of anti-HER2 drugs. The review suggested that the resistance of anti-HER2 drugs usually occurred by inducing CSC characteristics. TGF $\beta$ is a transforming growth cytokine and SMAD is an effector transforming factor in TGF $\beta$ signaling pathway. The acquisition of malignant features, such as EMT, cancer cell stemness, and drug resistance in cancer cells was closely related to TGF $\beta$-SMAD3 signaling pathway. Sustained stimulation of TGF $\beta$ could induce SMAD3 to phosphorylate intensely and enhance the CSC traits of $\mathrm{BC}$, thereby leading to HER2-positive BC resistance. Therefore, TGF $\beta$-SMAD3 pathway plays a vital role in inducing and maintaining resistance to antiHER2 drugs (Chihara et al., 2017). BCSCs undoubtedly participate in the process of resistance to HER2-positive $\mathrm{BC}$ too. Targeting BCSCs may be a possible way for us to solve the problem of resistance to anti-HER2 drugs.

\section{Therapeutic Strategies for Targeting Breast Cancer Stem Cells to Reverse Resistance}

Drug resistance has turned out to be one of major problems in $\mathrm{BC}$ therapy, while recent studies found that BCSCs are shown to be the culprit for this phenomenon. Nevertheless, the mechanisms of drug resistance mediated by BCSCs have not been fully understood. Currently, the following vital mechanisms are recognized to be related to treatment resistance, which include overexpression of ATP-binding cassette $(\mathrm{ABC})$ transporter and ALDH1, enhanced DNA repair mechanism, an altered cell cycle, resistance to apoptosis, and all microenvironment influences (Rebucci and Michiels, 2013; Smalley et al., 2013; Cojoc et al., 2015). Therefore, targeting these mechanisms may help us develop new therapies for BCSCs to reverse drug resistance in BC. We will discuss some of the current ways used to target BCSC below. The novel of therapeutic strategies for reversing drugresistance in BCSCs are displayed in Table 3 and Figure 4.

\section{Targeting Signaling Pathways}

Hedgehog (Hh) signaling is a crucial regulator of proliferation, maintenance, and self-renewal of BCSCs. There is a link between the activation of $\mathrm{HH}$ signaling and the over expression of MDR1 and ABCG2 in BCSCs. Targeting ABCG2 or MDR1 with cyclosporin $\mathrm{A}$, through inhibition of $\mathrm{HH}$ signaling, has shown to regulate and decrease the expression of ABCG2 and ABCG5 (Mao and Unadkat, 2015; Sims-Mourtada et al., 2015). HH signaling showed aberrant activation in Tamoxifen resistant cell lines; instead, knocking down the $\mathrm{HH}$ pathway can inhibit growth of tamoxifen resistant cells (Bhateja et al., 2019). Currently, two smoothened (SMO) inhibitors have made their way to clinical trials: GDC-0449 (vismodegib) with paclitaxel, epirubicin, and cyclophosphamide (NCT02694224), and LDE225 (sonidegib) combined with Docetaxel (NCT02027376). Both of the drugs were tested in triple negative BC (Hui et al., 2013; Cazet et al., 2018). It seems that oral HH inhibitors appear to be fairly safe throughout clinical testing.

Confirmatory evidence has recently revealed that the PI3K/ Akt/mTOR pathway plays a significant role in regulating BCSC pool. A study observed that Akt signaling altered the subcellular 
TABLE 2 | Resistance mechanisms for major drugs in BC therapy.

Drug resistance Related markers or pathways
Mode of action

\section{In vitro or \\ in vivo or \\ clinical tria \\ References}

Wang T. et al. (2018)

Paclitaxel resistance is regulated by JAK/STAT3-CPT1B-related fatty In vitro acid oxidation in BCSCs

Resistance to chemotherapy

Paclitaxe

JAK/STAT3-CPT1B-FAO-LPEs

MYC/MCL1-(mtOXPHOS) -(ROS)

$-\mathrm{HIF}-1 \alpha$

ROS-HIF1/2a-IL-6/IL-8/MDR1

EIF2AK3/EIF2AK4-pEIF2S1

ATF4

Jagged2- microRNA-200

IGF2BP3/CD44-IGF2-

Hedgehog signalling ABCB1

ABCB1/ABCG2

MTDH/NF-kb signalling

ERa-activated-DNMT1/DNMT3b MENA/MAPK signalling

Anthracyclines SLC34A2-Bmi1-ABCC5 signalling.

Glucosylceramide synthase

(GCS)

$\mathrm{HIF-2} \alpha / \mathrm{BCRP}$ axis

TOPOII

ANXA3/NF-kb signalling pathway

KLF4 signalling pathway

Resistance to endocrine Therapy

Tamoxifen

CD44 + CD24

Stem cell markers

ER signaling pathway

PI3K/AKT/mTOR signalling

IGFR

Wnt $/ \beta$-catenin pathway

Notch signalling

IL6/STAT3

Hh pathway

TGF- $\beta$ paclitaxel resistance is regulated by mitochondrial oxidative

phosphorylation (mtOXPHOS) via MYC/MCL1-(mtOXPHOS) - (ROS)-

HIF-1apathway in BCSCs

Chemotherapy-induced HIF activity enriched the BCSCs through IL-6 In vitro and IL-8 signaling and increased the expression of multidrug resistant proteins (MDR1)

Paclitaxel resistance is regulated by redox homoeostasis (ISR) in

BCSCs

Jagged2 promotes the maintenance of BCSCs properties and paclitaxel resistance by regulating the over-expression of microRNA200

CD44-expressing fibroblasts can inhibit paclitaxel-induced apoptosis, In vitro leading to paclitaxel resistance

Amplification of chromosome region $7 q 21$ coordinated the overexpression of resistance-related proteins and caused cancer cells

to develop multidrug resistance.

Atp binding cassette $(\mathrm{ABC})$ transporter linked to paclitaxel resistance -

MTDH reduces NF-kB expression and increases p65/p-p65 expression, causing paclitaxel resistance

In vitro

(Lee et al., 2017)

(Samanta et al., 2014)

In vitro and in Chen et al. (2019a) vivo

In vitro and in Li C. Y. et al. (2018) vivo

In vitro Liu Y. et al. (2017)

- $\quad$ (Genovese et al., 2017) (2015);

Robey et al. (2018)

In vitro and in (Yang et al., 2018) vivo

(S) vitro (Si et al., 2016) MENA subtype expression changes microtubule status after paclitaxel

Increases the expression of SLC34A2 in BCSCs induces

(Oudin et al., 2017)

in vivo

In vitro and in (Ge et al., 2016)

vivo

chemotherapy resistance to Dox through the slc34a2-bmi1-abcc5 signaling pathway.

The overexpression of GCS in BC cells is induced by Dox and is related to the pluripotency of BCSCs

In vitro and in (Bhinge et al., 2012) vivo

Chemotherapy-mediated HIF-2 $\alpha$ directly promotes the expression of In vitro

(He et al., 2019) BCRP and coordinates the ability of anti-dox in BCSCs.

Mesenchymal stem cells can effectively repair DNA double-strand In vitro ～(Nicolay et al., 2016) breaks induced by topoisomerase inhibitors resistance in BCSCs by the actvation of $\mathrm{NF}-\mathrm{kB}$ signalling pathway. vivo

Adriamyclins chemotherapy increased the expression of CD133, In vitro and in (Li et al., 2017) ALDH1A1, ABCG2, and the maintenance of BCSCs characteristics vivo

High CD44 + /CD24 - ratio is displayed in tamoxifen resistant $\mathrm{BC}$ In vitro Upregulates ALDH, Sox2,Oct4, and CXCR4 in tamoxifen resistant cells

(Wang et al., 2012)

(Piva et al., 2014;

Gwak et al., 2017;
Raffo et al., 2013;

Dubrovska et al., 2012;

Wang et al., 2012)

(Gelsomino et al., 2018)

Mutations in the ERa promote the generation of BCSCs markers and In vitro

$\begin{array}{ll}\text { Promotes self-renewal and survival of BCSCs in tamoxifen resistant } \quad \text { In vitro } & \text { (Gargini et al., 2015; } \\ \text { cells } & \text { Kolev et al., 2015) }\end{array}$ induce tamoxifen resistance

Maintains BCSCs surface markers expression and tumorigenesis by In vitro and in (Chang et al., 2013) the activation of AKT

vivo

Activation along with the enrichment BCSCs in tamoxifen resistant In vitro

(Loh et al., 2013;

Develops tamoxifen resistance via regulating BCSCs

In vitro

Angeloni et al., 2015)

Promotes BCSCs and stimulates tamoxifen resistance

(Magnifico et al., 2009;

Yun et al., 2013)

Maintains the self-renewal of BCSCs in response to tamoxifen

(Wang et al., 2012)

treatment

In vitro

(Ramaswamy et al., 2012)

Generates the phenotype of BCSCs and induces tamoxifen resistance

(Liu et al., 2012;

Kopp et al., 1995)

(Continued on following page) 
TABLE 2 | (Continued) Resistance mechanisms for major drugs in BC therapy.

\begin{tabular}{|c|c|c|c|c|}
\hline Drug resistance & Related markers or pathways & Mode of action & $\begin{array}{l}\text { In vitro or } \\
\text { in vivo or } \\
\text { clinical trial }\end{array}$ & References \\
\hline \multirow[t]{3}{*}{ Fulvestrant } & ER signaling pathway & $\begin{array}{l}\text { ER } \boldsymbol{\beta} \text { as a therapeutic target to in BCSCs to re-sensitizes fulvestrant } \\
\text { and tamoxifen resistant cells }\end{array}$ & $\begin{array}{l}\text { In vitro and in } \\
\text { vivo }\end{array}$ & (Ma et al., 2017) \\
\hline & Stem cell markers & $\begin{array}{l}\text { Up-regulation of ALDH1, NANOG, OCT4 and SOX2 in response to } \\
\text { tamoxifen or fulvestrant }\end{array}$ & In vitro & (Lillo et al., 2017) \\
\hline & $\mathrm{NOTCH}$ & Maintains the activity of BCSCs to resistant fulvestrant & $\begin{array}{l}\text { In vitro and in } \\
\text { vivo }\end{array}$ & (Simoes et al., 2015) \\
\hline Al & CD44/CD24 & High CD44 + /CD24 - ratio is demonstrated in Al-resistant cell & In vitro & $\begin{array}{l}\text { (Wang et al., 2013; } \\
\text { Uchiumi et al., 2019) }\end{array}$ \\
\hline \multirow[t]{5}{*}{ Letrozole } & $\begin{array}{l}\text { PI3K/Akt/mTOR signalling } \\
\text { pathway }\end{array}$ & $\begin{array}{l}\text { BCBSs-mediated letrozole resistance by regulating PI3K/Akt/mTOR } \\
\text { signaling pathway }\end{array}$ & In vitro & Liu Y. et al. (2019) \\
\hline & & $\begin{array}{l}\text { Promotes BCSCs enrichment in MCF-7, and inversing by } \\
\text { mTOR inhibitors }\end{array}$ & $\begin{array}{l}\text { In vitro and in } \\
\text { vivo }\end{array}$ & (Liu et al., 2014) \\
\hline & JNK signaling pathway & $\begin{array}{l}\text { Promotes the stemness of BC cells to cause aromatase } \\
\text { inhibitors resistance }\end{array}$ & In vitro & (Pelekanou et al., 2018) \\
\hline & Stem cell markers & Up-regulation of ALDH1, Oct 4, SOX2, and nanog in resistance cells & In vitro & (Nasr et al., 2018) \\
\hline & HER2 signaling & $\begin{array}{l}\text { Mediates Al resistance via regulation of stem cell markers, such as } \\
\text { breast cancer resistance protein (BCRP) }\end{array}$ & In vitro & (Gilani et al., 2012) \\
\hline $\begin{array}{l}\text { Letrozole or } \\
\text { exemestane }\end{array}$ & $\mathrm{HIF}-1 \boldsymbol{\alpha}$ & $\begin{array}{l}\text { Improves the generation of BCSCs to resistant to letrozole and } \\
\text { exemestane }\end{array}$ & In vitro & (Kazi et al., 2014) \\
\hline exemestane & RTKs pathway & Accumulates stemn-like cancer cells and resistant to exemestane & - & (Farahmand et al., 2018) \\
\hline \multirow[t]{3}{*}{ palbociclib } & PI3K/Akt/mTOR signalling & $\begin{array}{l}\text { Increases the ability of stemness and migration in palbociclib-resistant } \\
\text { BCSCs }\end{array}$ & In vitro & Chen et al. (2019b) \\
\hline & IL-6/STAT3 pathway & Promotes BCSCs enrichment & $\begin{array}{l}\text { In vitro and in } \\
\text { vivo }\end{array}$ & (Kettner et al., 2019) \\
\hline & EMT & $\begin{array}{l}\text { Promotes the capacity of migration and invasion via regulating BCSCs } \\
\text { in CDK4/6 inhibitor-resistant BC }\end{array}$ & $\begin{array}{l}\text { In vitro and in } \\
\text { vivo }\end{array}$ & $\begin{array}{l}\text { (Kettner et al., 2019; } \\
\text { Pandey et al., 2019) }\end{array}$ \\
\hline \multicolumn{5}{|c|}{ Resistance to Targeted Therapy } \\
\hline \multirow[t]{5}{*}{ Trastuzumab } & PI3K/AKT signalling & $\begin{array}{l}\text { Induces trastuzumab resistance via activating PI3K/AKT pathway in } \\
\text { BCSCs }\end{array}$ & $\begin{array}{l}\text { In vitro and in } \\
\text { vivo }\end{array}$ & (Choi et al., 2019) \\
\hline & JAK/STAT3 signalling & $\begin{array}{l}\text { STAT3 activation increases CSCs properties then results in } \\
\text { trastuzumab resistance }\end{array}$ & In vitro & (Chung et al., 2014) \\
\hline & Wnt/ $\beta$-catenin signalling & $\begin{array}{l}\text { Over-activating wnt signalling pathway promotes CSCs then leads to } \\
\text { trastuzumab resistance }\end{array}$ & In vitro & $\begin{array}{l}\text { (Wu et al., 2012; Choi } \\
\text { et al., 2019) }\end{array}$ \\
\hline & MUC1 & $\begin{array}{l}\text { The number of MUC1 increases in trastuzumb resistant cell lines while } \\
\text { anti-MUC1 inhibits CSCs proliferation }\end{array}$ & In vitro & (Sand et al., 2020) \\
\hline & $\mathrm{CD}_{4} 4^{+} / \mathrm{CD} 24^{-}$ & Acts as a predictor of poor response to trastuzumab & Clinical trial & (Seo et al., 2016) \\
\hline \multicolumn{5}{|l|}{ Trastuzumab } \\
\hline Lapatinib & TGF $\beta$ - Smad & Enhances the CSCs traits then leads to resistance of targeted therapy & In vitro & (Chihara et al., 2017) \\
\hline \multirow[t]{2}{*}{ Lapatinib } & PI3K/AKT signalling & Directly represses HER2 and indirectly inhibits EGFR & In vitro & $\begin{array}{l}\text { (lorio et al., 2009; De Cola } \\
\text { et al., 2015) }\end{array}$ \\
\hline & $\mathrm{CD}_{4} 4^{+} / \mathrm{CD} 24^{-}$ & Decreases the sensitivity of HER2+ BC cells to lapatinib & In vitro & (Hosonaga et al., 2014) \\
\hline
\end{tabular}

MTDH, Metadherin; ISR, The integrated stress response; MUC1, Mucin 1.

localization of BCRP, thereby regulating drug efflux activity in CSCs. Inhibitors of PI3K, which can not only be blocked via Akt signaling, resulted in the suppression of cancer cell proliferation, but also enhanced the sensitivity of chemoresistant cells (Hu et al., 2008). Another observation suggested that suppressing Akt that is downstream of HER2 signaling might efficiently target BCSCs in HER2-resistant tumors (Korkaya et al., 2009). Consequently, a series of PI3K and Akt selective inhibitors, which are being clinically investigated, demonstrates promising prospects.

Notch signaling is another pathway associated with treatment resistance. miR-34a regulates Notch-1 pathway in sustaining stem cell properties of BCSC populations, thereby suggesting that the miR-34a/Notch-1 pathway might be a potential therapeutic target for treating BC (Chen et al., 2016).
Activation of Notch signaling is regulated by a proteolytic enzyme $(\gamma$-secretase), so $\gamma$-secretase inhibitor is the most clinically promising candidate in reversing drug resistance (Real and Ferrando, 2009). Psoralidin had been shown to effectively inhibits BCSCs proliferation and self-renewal through downregulating Notch1 signaling (Suman et al., 2013). Besides, vitamin D compounds showed activity against BCSCs by impeding the expression of Notch signaling components, such as Notch1, Notch2, Notch3, JAG1, and JAG2 (Shan et al., 2017). Meanwhile, a study showed that targeting FGFR mitochondrial metabolism-Notch1 axis may be effective to abrogate drug-resistant CSCs in TNBC (Bhola et al., 2016). Hence, Notch signaling pathway plays an important role in drug resistance mediated by BCSCs. 


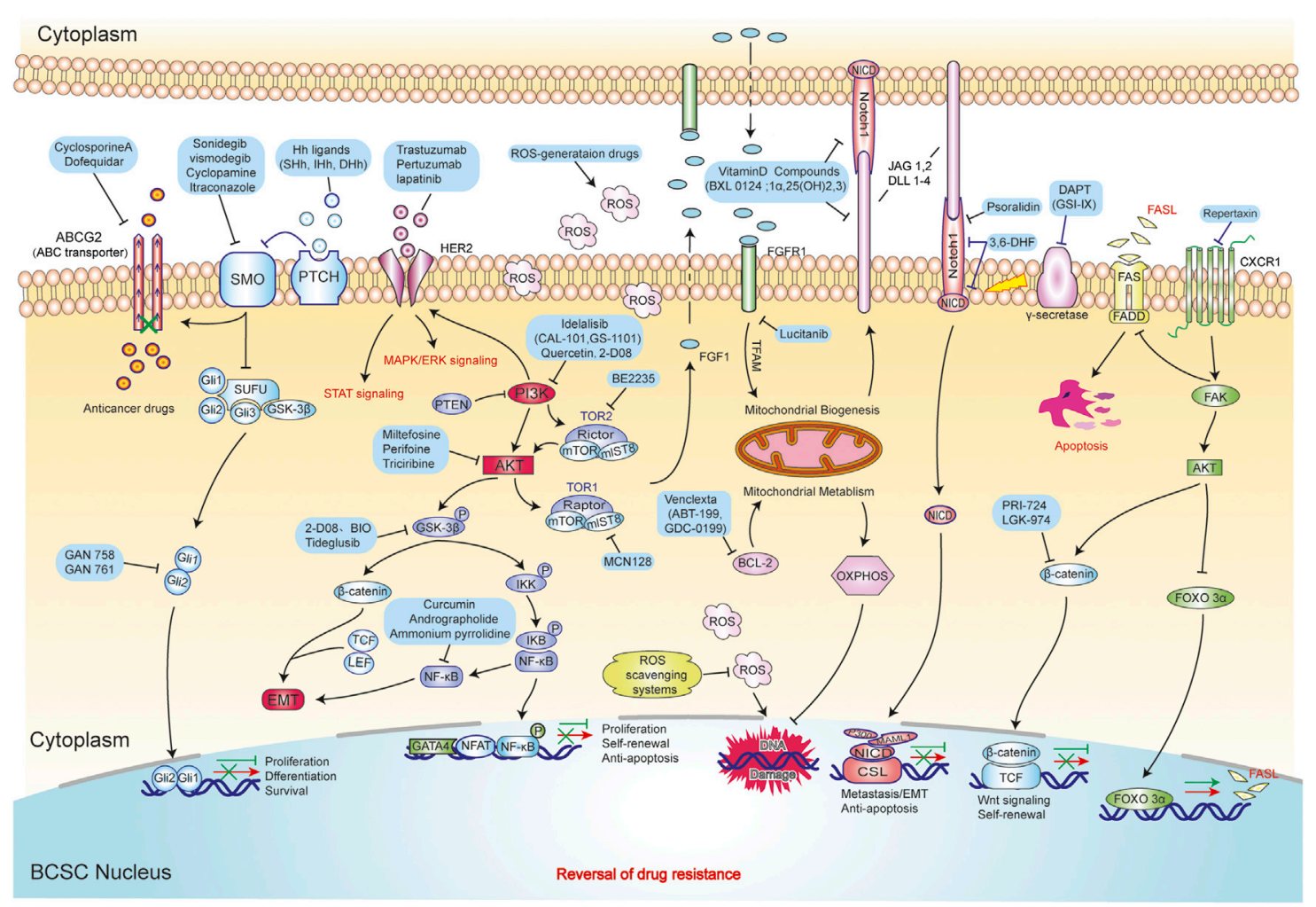

FIGURE 4 | The novel strategies of drug resistance reversal in BCSCs. These strategies mainly include inhibited proliferation ability (Hh, NF-kB signaling pathway) and self-renewal ability (EMT and Wnt/ $\beta$-catenin signaling pathway), promoted DNA damage (ROS scavenging system and Mitochondrial metabolism) and apoptosis (Notch and FOXO/FASL/FAS signaling pathway).

\section{Targeting Tumor Microenvironment}

G-protein coupled receptors (GPCRs) are very important in the survival of BCSCs before and after the chemotherapy process. Chemokine receptors CXCR1 and CXCR2 generally play a role in chemotaxis of neutrophils, macrophages, and endothelial cells in a physiological microenvironment. Antagonizing CXCR1 by CXCR1-neutralizing antibody or by the small molecule inhibitor repertaxin selectively depleted more BCSCs than bulk tumor cells in vitro. This was followed by massive apoptosis of bulk tumor cells through FASL/FAS signaling via FAK/AKT/FOXO3A pathway (Ginestier et al., 2010). Repertaxin has already shown satisfactory effects in Phase I trials. Moreover, the chemokine receptor CXCR4 is expressed in BCSCs and forms a target in restraining or removal of BCSCs. Activation of this receptor is thought to facilitate the metastasis of mesenchymal BCSCs. CXCR4 probably stimulated the extracellular signal regulated kinase (ERK) pathway in BCSCs by activating PKA/MAPKAP2 pathway (Yi et al., 2014), thus providing resources for the research of BCSCtargeted cancer therapy through blocking these pathways by inhibiting receptors.

\section{Targeting Breast Cancer Stem Cell Metabolism}

The induction of oxidative stress is an important mechanism of action for many anticancer agents. BCSCs possess a highly active
DNA repair system, which repairs DNA damages, particularly after chemotherapy treatment. Previous trials suggested that the ability of BCSCs to repair DNA damage is significantly related to reactive oxygen species (ROS), the levels of ROS are markedly lower in BCSCs than in non-CSCs (NCSCs) due to the high expression of free radical scavenging systems in BCSCs, such as superoxide dismutase, catalase, and glutathione peroxidase, which keep them from genotoxic damage of ROS. Thus, reduction of ROS scavengers in BCSCs markedly decreased their clonogenicity and resulted in therapeutic sensitization (Phillips et al., 2006; Diehn et al., 2009). Through $\mathrm{H}_{2} \mathrm{O}_{2}$ induced BCSC loss of function, ROS-generating drugs may have the therapeutic potential to eradicate drug-resistant BCSCs via induction of premature senescence (Zhong et al., 2019). Moreover, increasing mitochondrial activity is associated with resistance to DNA damage in BC. BCSCs are obviously dependent on glucose and mitochondrial metabolism. BCL-2 protein is a famous regulator of mitochondrial metabolism, inhibition of BCL-2 can result in the inhibition of oxidative phosphorylation (OXPHOS), which will lead to the reduction of BCSCs depending on OXPHOS (Deshmukh et al., 2016).

Besides potentiated ROS scavenging systems, BCSCs can protect themselves from several chemotherapeutic drugs which target the cell cycle process by maintaining a quiescent state in G0 
TABLE 3 | Therapeutic strategies to reversing drug-resistance in BCSCs.

$\begin{array}{lcc}\text { Drug/Compound } \quad \text { Target } & \text { Mode of action } & \text { In vitro or } \\ \text { in vivo or } & \text { clinical trial }\end{array}$

\section{Surface markers \\ HA-decorated \\ nanoparticles and \\ salinomycin \\ Doxycycline \\ Lentivirus-mediated \\ CD44 shRNA \\ CD133-targeted \\ polymeric nanoparticles \\ scFv- PE38KDEL \\ Quercetin \\ Withaferin A \\ Benztropine mesylate \\ Deptropine citrate \\ Signaling pathway \\ Cyclopamine \\ Monoclonal antibody \\ (5E1) \\ Nitidine chloride

GANT61 (gli protein
inhibitor)
Vismodegib

Sonidegib

NVPBGT226

Perifosine

Everolimus (RAD001)

MK2206

PF-03084014

(nirogacestat)

MK-0752

LY3039478

(crenigacestat)

Capsaicin

Psoralidin

RO4929097 (RG-

4733)

Foxy-5

Wnt $/ \beta$-catenin

Sulforaphane

Microenvironment

AMD3100 (CXCR4

antagonist)

Reparixin

Evofosfamide (TH-302) Hypoxia

Echinomycin

Tumor metabolism

CD44

CD44, ALDH1

CD44

CD133

CD133

ALDH

PI3K signaling

\section{SDF-I/CXCR4}

Hedgehog signaling

Notch signaling

CXCR signaling

Hypoxia response element Reduces cytotoxic in breast cancer cells

of CD44-HA-Nanoparticles loaded with

salinomycin

Inhibits BCSCs by apoptosis

Sensitizes BCSCs to doxorubicin

Promotes BCSCs apoptosis by inducing cytotoxicity

Bmi-1 BCSCs

Suppresses the activation of the SMO

transmembrane receptor protein

Inhibits expression of glioma-associated

oncogene in the $\mathrm{Hh}$ signaling pathway

Sensitizes BC cells to commonly used

Hedgehog signaling

sensitize $B C$ cells to docetaxel

advanced breast cancer

cancer cells

inhibitor

apoptosis

by blocking notch signaling strong modulation of Notch signaling notch signaling

Inhibits the entry of NICD to nuclear

Promotes apoptosis and inhibits BCSCs

proliferation and repairing

notch signaling

Simulates the effect of Wnt5a to inhibits

metastasis

Inhibits BCSCs self-renewal by the

signaling
Increases efficiency of drug delivery by the system In vitro

Clinical trial

In vitro

Reduces tumor initiating cell by conjugating anti- In vivo CD133 monoclonal antibody to nanoparticles

Inhibits expression of Sox2, Oct4, nanog, and

Inhibits sphere formation and self-renewal of

In vitro and in

vivo

In vitro

In vitro

In vitro and in

vivo

In vivo

(Muntimadugu et al., 2016)

Inhibits breast cancer growth and metastasis.

In vivo

Inhibits the stemness of BCSCs by downregulates In vitro

the marker of CD44

In vitro

chemotherapy drugs by the inactivation of

Inhibits the expression of BCSCs markers to

In vitro and in

vivo

Novel ATP-competitive mTOR kinase inhibitors for In vitro and in

vivo

Restores Tamoxifen sensitivity in resistant breast In vitro

Sensitizes advanced breast cancer to aromatase Clinical trial

Inhibits growth and induces breast cancer cells Clinical trial

Sensitizes BCSCs to known chemotherapy drugs In vitro and

clinical trial

Promotes the sensitivity of BCSCs to docetaxel by In vitro, in vivo and clinical trial $\gamma$-secretase inhibitor to promote inactivation of Clinical trial

$\gamma$-secretase inhibitor to promote inactivation of

downregulation of the wnt $/ \beta$-catenin signaling.

Inhibits BCSC self-renewal and maintenance

In vitro

Induces BCSCs apoptosis through FASL/FAS

Suppresses BC growth by selectively cytotoxic

In vitro and

clinical trial

In vitro and in

vivo

In vitro
(Scatena et al., 2018)

(Hu et al., 2016)

(Swaminathan et al., 2013)

(Ohlfest et al., 2013)

Wang R. et al. (2018)

Kim and Singh (2014)

(Cui et al., 2017)

(Kubo et al., 2004)

(O'Toole et al., 2011)

(Sun et al., 2016)

(Koike et al., 2017)

(Hui et al., 2013; Palomeras et al., 2018)

(Cazet et al., 2018; Palomeras et al., 2018)

(Cidado and Park, 2012)

(Farahmand et al., 2018)

(Baselga et al., 2012)

(Chien et al., 2019)

Zhang C. C. et al. (2012); (Zhang and Grivennikov 2013); Locatelli et al., (2017); Ocana et al., 2010)

(Aktas et al., 2009; Schott et al., 2013;

Venkatesh et al., 2018)

(McCartney et al., 2018)

(Shim and Song, 2015)

(Suman et al., 2013)

(Strosberg et al., 2012; Koury et al., 2017; Venkatesh et al., 2018)

(Canesin et al., 2017; Palomeras et al., 2018. Goldsberry et al., 2019)

(Li et al., 2010)

Liu B. Q. et al. (2017)

(Schott et al., 2013)

(Liapis et al., 2016)

(Lathan and Von Hoff, 1984)

(Continued on following page) 
TABLE 3 | (Continued) Therapeutic strategies to reversing drug-resistance in BCSCs.

\begin{tabular}{|c|c|c|c|c|}
\hline Drug/Compound & Target & Mode of action & $\begin{array}{l}\text { In vitro or } \\
\text { in vivo or } \\
\text { clinical trial }\end{array}$ & References \\
\hline VLX600 & Mitochondrial OXPHOS & Makes BCSCs death by inhibiting BCL-2 & In vitro & (Dey et al., 2019) \\
\hline Etomoxir & $\begin{array}{l}\text { Carnitine } \\
\text { palmitoyltransferase-1 } \\
\text { inhibitor }\end{array}$ & Activates metabolic by cAMP-induced & In vitro & (Manerba et al., 2019) \\
\hline Salinomycin & Sodium potassium gradient & $\begin{array}{l}\text { Selectively eradicates BCSCs selectively via } \\
\text { lysosomal iron Targeting. }\end{array}$ & In vitro & (Versini et al., 2020) \\
\hline XCT790 & ERRn-PGC1 & $\begin{array}{l}\text { Targets FOXM1 and mitochondrial biogenesis to } \\
\text { block both the survival and propagation of BCSCs }\end{array}$ & In vitro & (De Luca et al., 2015) \\
\hline \multicolumn{5}{|c|}{ 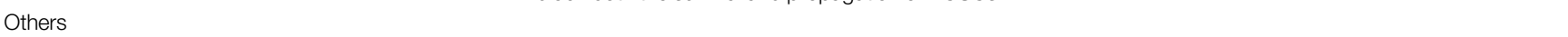 } \\
\hline MS-209 & P-glycoprotein & Makes BCSCs more sensitive to docetaxel & $\begin{array}{l}\text { In vitro and in } \\
\text { vivo }\end{array}$ & (Naito et al., 2002) \\
\hline Glucosamine & STAT 3 & Inhibits BCSCs the ability to form mammosphere & In vitro & (Hosea et al., 2018) \\
\hline Apigenin & Hippo & $\begin{array}{l}\text { Inhibits BCSCs migration and metastasis by } \\
\text { downregulating transcription activity of TAZ and } \\
\text { YAP1 }\end{array}$ & $\begin{array}{l}\text { In vitro and in } \\
\text { vivo }\end{array}$ & (Li et al., 2018) \\
\hline MLN4924 & Sox-2 & $\begin{array}{l}\text { Suppresses stem cell property and makes breast } \\
\text { cancer cells more sensitive of tamoxifen }\end{array}$ & In vitro & (Yin et al., 2019) \\
\hline $\mathrm{MR} \times 34$ & MiR-34a & $\begin{array}{l}\text { Contains miR-34a mimic and a lipid vector and } \\
\text { inhibits cellular proliferation, invasion and tumor } \\
\text { sphere formation. }\end{array}$ & $\begin{array}{l}\text { In vitro, in vivo } \\
\text { and clinical trial }\end{array}$ & $\begin{array}{l}\text { (Adams et al., 2016; Mohammady et al., } \\
\text { 2019) }\end{array}$ \\
\hline $\boldsymbol{\alpha E P C R}-1535$ & Protein C receptor & Attenuates tumor growth & In vitro & (Schaffner et al., 2013) \\
\hline
\end{tabular}

NICD, Notch intracellular membrane domain.

phase (Yoshida and Saya, 2016). BCSCs can adopt dormancyassociated phenotypes through upregulating autophagic pathways (Vera-Ramirez et al., 2018). Salinomycin is a kind of ionophore antibiotic, which has been shown to be effective in clearing BCSCs through autophagy (Jiang et al., 2018). Recently, studies showed that the mechanistic link between autophagy and metastastic dormancy was associated with Spleen Tyrosine Kinase (SYK) in epithelial-mesenchymal transition (EMT) required for BC metastasis. Fostamatinib, a SYK pharmacologic inhibitior, prevents mesenchymal-epithelial transition (MET), which can inhibit metastatic tumor outgrowth (Shinde et al., 2019). Currently, tyrosine kinase inhibitors are being tested in clinical trials.

\section{Nano-therapeutics Against Breast Cancer Stem Cell}

Nanoparticle (NP)-mediated therapy is an effective delivery strategy for cancer therapeutics. It contributes to specific delivery of a chemotherapeutic drug, RNAi, or antibodies to the stem cell population by recognizing antibodies/aptamers against BCSC-specific markers.

CD44 is the first discovered and the most commonly used surface marker of BCSCs, which plays an important role in all aspects of tumor cells, such as growth and proliferation, migration, differentiation, apoptosis, self-renewal, microenvironment, EMT, and drug resistance (Jin et al., 2017). As a cell receptor, CD44 mediates the communication with the microenvironment through interacting with certain extracellular ligands. For the past few years, the development of an antibody against CD44, which could induce BCSCs terminal differentiation, had already been found to be effective and has been gradually accepted (Naor et al., 1997). In aggressive BC, the combination of anti-human CD44 monoclonal antibody with doxorubicin and cyclophosphamide using NPs has been used to prevent tumor recurrence (Fan et al., 2010; Wu et al., 2017).

Micro RNAs (miRs) play a key role in the sustenance and heterogeneity of BCSCs in $\mathrm{BC}$. They can regulate proteins associated with drug resistance in human BC. For instance, miR-21 may facilitate the inhibition of tumor proliferation, growth, and migration (Han et al., 2012); miR-100 inhibits self-renewal of BCSCs and tumorigenesis (Deng et al., 2014); miR-199a can increase stem cell properties in BCSCs (CeliaTerrassa et al., 2017). miR-205-5p is highly expressed in BCSCs and is related to therapy resistance (De Cola et al., 2015). Moreover, research shows that the high expression of STAT3 affects doxorubicin resistance of BCSCs, and miR-124 reverses this resistance of BCSCs through targeting STAT3 to control the HIF-1 signaling pathway (Liu C. et al., 2019). Consequently, targeting miRs and delivering siRNAs to tumors using NPs is an effective strategy to reverse drug resistance and enhance drug efficacy.

Aldehyde dehydrogenase 1 (ALDH1) is a $\mathrm{NAD}(\mathrm{P})+-$ dependent enzyme, which is the key enzyme to oxidize intracellular aldehydes to carboxylic acids. ALDH1 is found to be highly active in BCSCs, increasing their proficiency by removing toxic oxygen radicals from the tumor microenvironment (Charafe-Jauffret et al., 2013). By consulting relevant literatures, we also found that the increased levels of ALDH family members were correlated with chemoresistance (Croker et al., 2009; Tanei et al., 2009). ALDHs inhibition sensitizes BCSCs to chemotherapy (Croker and Allan, 2012). NPs containing doxorubicin and chloroquine have been shown to reduce ALDH high population of MDA-MB231 cells (Li et al., 2015), and several ALDH inhibitors are currently in the preclinical stage. 


\section{Other Therapeutic Approaches}

CSCs manifest a high number of proteins on their cell surface, such as $\mathrm{ABC}$ transporters, $\mathrm{ABCB} 1$ (P-gp, MDR1), ABCG2 (BCRP1), $A B C C 11$ (MRP8), and $A B C B$, which are strongly expressed in CSC's chemo-resistance (Dean, 2009). How do CSCs develop drug resistance through the protein molecule above? In $\mathrm{BC}$, a recent study has indicated that the prominently activated ATP binding cassette (ABC) or drug efflux pump of BCSCs can successfully pump out chemotherapeutic drugs, such as anthracycline or taxanes, which are known as the most essential drugs of $\mathrm{BC}$ treatment (Cojoc et al., 2015). Furthermore, other scholars have found that an increased level of ABCG2 in BCSCs enabled rapid expulsion of cytotoxic drugs, conferring cellular resistance to antitumor drugs (Hirschmann-Jax et al., 2004). A recent study has confirmed that SOX2-ABCG2-TWIST1 axis can promote stemness and chemoresistance in TNBC, further indicating that $\mathrm{ABC}$ proteins are potential targets for BCSCs eradication (Mukherjee et al., 2017). Dofequidar, an ABC transporter inhibitor, could increase the sensitivity of BCSC to anticancer drugs; it showed promising results in patients with advanced or recurrent $\mathrm{BC}$ when combined with other chemotherapeutic agents, such as cyclophosphamide, doxorubicin, and fluorouracil (Saeki et al., 2007). Additionally, SOX2 is a key transcription factor that plays critical roles in maintaining stem cell properties and conferring drug resistance. MLN4924 can repress the expression of SOX2, leading to suppression of stem cell properties and sensitization of BC cells to tamoxifen (Yin et al., 2019).

\section{CONCLUSION}

$\mathrm{BC}$ remains the most frequent cancer in women, and significant public health issue globally (Zavala et al., 2019). Both of the developing and developed world are suffering from BC incidence and mortality (Global Burden of Disease Cancer Collaboration et al., 2015). Due to limitations of therapeutic strategies, it is urgent to explore novel and effective strategies. The important role of BCSCs in drug resistance, recurrence, and metastasis of BC has attracted more and more attention. Many studies have also enlightened the drug resistance mechanism of BCSCs. Currently, various treatments targeting BCSCs have been in preclinical and clinical trials. Unfortunately, the mechanism of drug resistance that is controlled by BCSC rarely functions individually. In the process of antagonizing anticancer drugs, these mechanisms interact with each other and form a complex functional network of drug resistance.

\section{REFERENCES}

Abad, E Graifer, D, and Lyakhovich, A. (2020). DNA damage response and resistance of cancer stem cells. Cancer Lett. 474, 106-117. doi:10.1016/j. canlet.2020.01.008

Adams, B. D., Parsons, C., and Slack, F. J. (2016). The tumor-suppressive and potential therapeutic functions of miR-34a in epithelial carcinomas. Expert Opin. Ther. Targets 20, 737-753. doi:10.1517/14728222.2016.1114102

Aktas, B., Tewes, M., Fehm, T., Hauch, S., Kimmig, R., and Kasimir-Bauer, S. (2009). Stem cell and epithelial-mesenchymal transition markers are frequently
Hence, inhibiting a drug resistant pathway is likely to trigger feedback mechanisms that ultimately allow BCSCs to escape the effects of the drug. Therefore, the therapy based on the combination of multiple targets for BCSCs' functional network is the most promising approach. Furthermore, existing nanobiology technologies should be fully utilized, through finding specific surface markers of targeting BCSCs, to locate and eliminate BCSCs accurately. Recently, biologically and chemically synthesized gold nanoparticles (AuNPs) (Virmani et al., 2019), silver nanoparticles (AgNPs) (Muthupandian et al., 2019) and selenium nanoparticles (SeNPs) (Vahidi et al., 2020) have attracted significant attention for their anticancer effects against cancers such as lung cancer, colorectal Cancer (Barabadi et al., 2020a), cervical cancer (Barabadi et al., 2020b) and prostate cancer (Barabadi et al., 2019a). Fortunately, AuNPs (Barabadi et al., 2019b) and AgNPs (Saravanan et al., 2020) have also been reported to play an important role in the treatment of BC. With the development of cancer nanomedicine, it is expected that biologically and chemically synthesized NPs may emerge as potential BCSCs therapeutic agents alone or in combination with anti-cancer drugs before long of future. In conclusion, these therapies targeting BCSCs will lay the foundation for reversing drug resistance and attaining favorable prognosis in $\mathrm{BC}$.

\section{AUTHOR CONTRIBUTIONS}

QZ and MZ conceived and drafted the manuscript. LZ and XM discussed the concepts of the manuscript. QZ drew the figures. LZ and XM approved the version to be submitted.

\section{FUNDING}

This work was supported by a special program from the Ministry of Science and Technology of China (2016YFA0502500 to LZ), the Chinese National Natural Science Funds (91753139 to LZ and 81973861 to $\mathrm{XM}$ ), the Zhejiang Natural Science Fund (LD19C070001 to LZ).

\section{ACKNOWLEDGMENTS}

We would like to apologize to those researchers whose related work we were not able to cite in this review.

overexpressed in circulating tumor cells of metastatic breast cancer patients Breast Cancer Res. 11, R46. doi:10.1186/bcr2333

Alexe, G., Alexe, S, Axelrod, D. E., Bonates, T. O, Lozina, I. I., Reiss, M., and Hammer, P. L. (2006). Breast cancer prognosis by combinatorial analysis of gene expression data. Breast Cancer Res. 8, R41. doi:10.1186/bcr1512

Al-Hajj, M., Wicha, M. S, Benito-Hernandez, A, Morrison, S. J., and Clarke, M. F. (2003). Prospective identification of tumorigenic breast cancer cells. Proc. Natl. Acad. Sci. U.S.A. 100, 3983-3988. doi:10.1073/pnas.0530291100

Alves, C. L., Elias, D., Lyng, M., Bak, M., Kirkegaard, T., Lykkesfeldt, A. E, and Ditzel, H. J. (2016). High CDK6 Protects Cells from Fulvestrant-Mediated Apoptosis and is a Predictor of Resistance to Fulvestrant in Estrogen Receptor- 
Positive Metastatic Breast Cancer. Clin. Cancer Res. 22, 5514-5526. doi:10. 1158/1078-0432.CCR-15-1984

Angeloni, V., Tiberio, P., Appierto, V., and Daidone, M. G. (2015). Implications of stemness-related signaling pathways in breast cancer response to therapy. Semin. Cancer Biol. 31, 43-51. doi:10.1016/j.semcancer.2014.08.004

Arnason, T., and Harkness, T. (2015). Development, maintenance, and reversal of multiple drug resistance: at the crossroads of TFPI1, $\mathrm{ABC}$ transporters, and HIF1. Cancers 7, 2063-2082. doi:10.3390/cancers7040877

Arpino, G., Wiechmann, L., Osborne, C. K., and Schiff, R. (2008). Crosstalk between the estrogen receptor and the HER tyrosine kinase receptor family: molecular mechanism and clinical implications for endocrine therapy resistance. Endocr. Rev. 29, 217-233. doi:10.1210/er.2006-0045

Baccelli, I., Schneeweiss, A., Riethdorf, S., Stenzinger, A., Schillert, A., Vogel, V., et al. (2013). Identification of a population of blood circulating tumor cells from breast cancer patients that initiates metastasis in a xenograft assay. Nat. Biotechnol. 31, 539-544. doi:10.1038/nbt.2576

Bai, X., Ni, J., Beretov, J., Graham, P., and Li, Y. (2018). Cancer stem cell in breast cancer therapeutic resistance, Cancer Treat Rev. 69, 152-163. doi:10.1016/j.ctrv. 2018.07.004

Baker, A., Wyatt, D., Bocchetta, M., Li, J., Filipovic, A., Green, A., et al. (2018). Notch-1-PTEN-ERK1/2 signaling axis promotes HER2+ breast cancer cell proliferation and stem cell survival. Oncogene 37, 4489-4504. doi:10.1038/ s41388-018-0251-y

Bane, A., Viloria-Petit, A., Pinnaduwage, D., Mulligan, A. M., O'Malley, F. P., and Andrulis, I. L. (2013). Clinical-pathologic significance of cancer stem cell marker expression in familial breast cancers. Breast Cancer Res. Treat. 140, 195-205. doi:10.1007/s10549-013-2591-1

Barabadi, H., Kamali, K. D., Shoushtari, F. J., Tajani, B., and Saravanan, M. (2019a). Emerging theranostic silver and gold nanomaterials to combat prostate cancer: a systematic review. J. Cluster Sci. 30 (6), 1375-1382. doi:10.1007/s10876-01901588-7

Barabadi, H., Mahjoub, M. A., Tajani, B., Ahmadi, A., Junejo, Y., and Saravanan, M. (2019b). Emerging theranostic biogenic silver nanomaterials for breast cancer: a systematic review. J. Cluster Sci. 30 (2), 259-279. doi:10.1007/s10876-01801491-7

Barabadi, H., Vahidi, H., Kamali, K. D., Rashedi, M., and Muthupandian, S. (2020a). Emerging theranostic silver nanomaterials to combat colorectal cancer: a systematic review. J. Cluster Sci. 31, 311-321. doi:10.1007/ s10876-019-01668-8

Barabadi, H., Vahidi, H., Kamali, K. D., Rashedi, M., and Saravanan, M. (2020b). Antineoplastic biogenic silver nanomaterials to combat cervical cancer: a novel approach in cancer therapeutics. J. Cluster Sci. 31 (4), 659-672. doi:10.1007/ s10876-019-01697-3

Barker, N., Ridgway, R. A., van Es, J. H., van de Wetering, M., Begthel, H., van den Born, M., et al. (2009). Crypt stem cells as the cells-of-origin of intestinal cancer. Nature 457, 608-611. doi:10.1038/nature07602

Baselga, J., Campone, M., Piccart, M., Burris, H. A., Rugo, H. S., Sahmoud, T., et al. (2012). Everolimus in postmenopausal hormone-receptor-positive advanced breast cancer. N. Engl. J. Med. 366, 520-529. doi:10.1056/NEJMoa1109653

Battula, V. L., Shi, Y., Evans, K. W., Wang, R. Y., Spaeth, E. L., Jacamo, R. O., et al. (2012). Ganglioside GD2 identifies breast cancer stem cells and promotes tumorigenesis. J. Clin. Invest. 122, 2066-2078. doi:10.1172/JCI59735

Battula, V. L., Nguyen, K., Sun, J., Pitner, M. K., Yuan, B., Bartholomeusz, C., et al. (2017). IKK inhibition by BMS-345541 suppresses breast tumorigenesis and metastases by targeting GD2+ cancer stem cells. Oncotarget 8, 36936-36949. doi:10.18632/oncotarget.16294

Berns, K., Horlings, H. M., Hennessy, B. T., Madiredjo, M., Hijmans, E. M., Beelen, K., et al. (2007). A functional genetic approach identifies the PI3K pathway as a major determinant of trastuzumab resistance in breast cancer. Cancer Cell 12, 395-402. doi:10.1016/j.ccr.2007.08.030

Bhateja, P., Cherian, M., Majumder, S., and Ramaswamy, B. (2019). The hedgehog signaling pathway: a viable target in breast cancer?. Cancers (Basel) 11 (8), 1126. doi:10.3390/cancers 11081126

Bhinge, K. N., Gupta, V., Hosain, S. B., Satyanarayanajois, S. D., Meyer, S. A., Blaylock, B., et al. (2012). The opposite effects of doxorubicin on bone marrow stem cells versus breast cancer stem cells depend on glucosylceramide synthase. Int. J. Biochem. Cell Biol. 44, 1770-1778. doi:10.1016/j.biocel.2012.06.010
Bhola, N. E., Balko, J. M., Dugger, T. C., Kuba, M. G., Sanchez, V., Sanders, M., et al. (2013). TGF- $\beta$ inhibition enhances chemotherapy action against triple-negative breast cancer. J. Clin. Invest. 123, 1348-1358. doi:10.1172/JCI65416

Bhola, N. E., Jansen, V. M., Koch, J. P., Li, H., Formisano, L., Williams, J. A., et al. (2016). Treatment of triple-negative breast cancer with TORC1/2 inhibitors sustains a drug-resistant and notch-dependent cancer stem cell population. Cancer Res. 76, 440-452. doi:10.1158/0008-5472.CAN-15-1640-T

Bock, C., Kuhn, C., Ditsch, N., Krebold, R., Heublein, S., Mayr, D., et al. (2014). Strong correlation between N-cadherin and CD133 in breast cancer: role of both markers in metastatic events. J. Cancer Res. Clin. Oncol. 140, 1873-1881. doi:10.1007/s00432-014-1750-z

Borgna, S., Armellin, M., di Gennaro, A., Maestro, R., and Santarosa, M. (2012). Mesenchymal traits are selected along with stem features in breast cancer cells grown as mammospheres. Cell Cycle 11, 4242-4251. doi:10.4161/cc. 22543

Bourguignon, L. Y., Singleton, P. A., Zhu, H., and Diedrich, F. (2003). Hyaluronanmediated CD44 interaction with RhoGEF and Rho kinase promotes Grb2associated binder-1 phosphorylation and phosphatidylinositol 3-kinase signaling leading to cytokine (macrophage-colony stimulating factor) production and breast tumor progression. J. Biol. Chem. 278, 29420-29434. doi:10.1074/jbc.M301885200

Bourguignon, L. Y., Singleton, P. A., Diedrich, F., Stern, R., and Gilad, E. (2004). CD44 interaction with $\mathrm{Na}+\mathrm{H}+$ exchanger (NHE1) creates acidic microenvironments leading to hyaluronidase- 2 and cathepsin B activation and breast tumor cell invasion. J. Biol. Chem. 279, 26991-27007. doi:10. 1074/jbc.M311838200

Bourguignon, L. Y. W. (2019). Matrix hyaluronan-CD44 interaction activates MicroRNA and LncRNA signaling associated with chemoresistance, invasion, and tumor progression. Front. Oncol 9, 492. doi:10.3389/fonc.2019.00492

Bourguignon, L. Y., Wong, G., Earle, C., Krueger, K., and Spevak, C. (2010). Hyaluronan-CD44 interaction promotes $\mathrm{c}$-Src-mediated twist signaling, microRNA-10b expression, and RhoA/RhoC up-regulation, leading to Rhokinase-associated cytoskeleton activation and breast tumor cell invasion. J. Biol. Chem., 285, 36721-36735. doi:10.1074/jbc.M110.162305

Bousquet, G., El Bouchtaoui, M., Sophie, T., Leboeuf, C., de Bazelaire, C., Ratajczak, P., et al. (2017). Targeting autophagic cancer stem-cells to reverse chemoresistance in human triple negative breast cancer. Oncotarget 8, 35205-35221. doi: doi:10.18632/oncotarget.16925

Brugnoli, F., Grassilli, S., Lanuti, P., Marchisio, M., Al-Qassab, Y., Vezzali, F., et al. (2017). Up-modulation of PLC-beta2 reduces the number and malignancy of triple-negative breast tumor cells with a $\mathrm{CD} 133(+) / \operatorname{EpCAM}(+)$ phenotype: a promising target for preventing progression of TNBC. BMC Cancer 17, 617. doi:10.1186/s12885-017-3592-y

Bumbaca, B., and Li, W. (2018). Taxane resistance in castration-resistant prostate cancer: mechanisms and therapeutic strategies. Acta Pharm. Sin. B 8, 518-529. doi:10.1016/j.apsb.2018.04.007

Canesin, G., Evans-Axelsson, S., Hellsten, R., Krzyzanowska, A., Prasad, C. P., Bjartell, A., et al. (2017). Treatment with the WNT5A-mimicking peptide Foxy5 effectively reduces the metastatic spread of WNT5A-low prostate cancer cells in an orthotopic mouse model. PLoS One 12, e0184418. doi:10.1371/journal. pone. 0184418

Capeloa, T., Benyahia, Z., Zampieri, L. X., Blackman, M. C. N. M., and Sonveaux, P. (2020). Metabolic and non-metabolic pathways that control cancer resistance to anthracyclines. Semin. Cell Dev. Biol. 98, 181-191. doi:10.1016/j.semcdb.2019. 05.006

Cazet, A. S., Hui, M. N., Elsworth, B. L., Wu, S. Z., Roden, D., Chan, C. L., et al. (2018). Targeting stromal remodeling and cancer stem cell plasticity overcomes chemoresistance in triple negative breast cancer. Nat. Commun. 9, 2897. doi:10. 1038/s41467-018-05220-6

Celia-Terrassa, T., Liu, D. D., Choudhury, A., Hang, X., Wei, Y., Zamalloa, J., et al. (2017). Normal and cancerous mammary stem cells evade interferon-induced constraint through the miR-199a-LCOR axis. Nat. Cell Biol. 19, 711-723. doi:10.1038/ncb3533

Chakraborty, A. K., Welsh, A., and Digiovanna, M. P. (2010). Co-targeting the insulin-like growth factor I receptor enhances growth-inhibitory and proapoptotic effects of anti-estrogens in human breast cancer cell lines. Breast Cancer Res. Treat. 120 327-335. doi:10.1007/s10549-009-0382-5 
Chan, Y. T., Lai, A. C., Lin, R. J., Wang, Y. H., Wang, Y. T., Chang, W. W., et al. (2020). GPER-induced signaling is essential for the survival of breast cancer stem cells. Int. J. Cancer 146. 1674-1685. doi:10.1002/ijc. 32588

Chang, W. W., Lin, R. J., Yu, J., Chang, W. Y., Fu, C. H., Lai, A., et al. (2013). The expression and significance of insulin-like growth factor-1 receptor and its pathway on breast cancer stem/progenitors, Breast Cancer Res. 15, R39. doi:10. $1186 / \mathrm{bcr} 3423$

Charafe-Jauffret, E., Ginestier, C., Bertucci, F., Cabaud, O., Wicinski, J., Finetti, P., et al. (2013). ALDH1-positive cancer stem cells predict engraftment of primary breast tumors and are governed by a common stem cell program. Cancer Res 73 , 7290-7300. doi:10.1158/0008-5472.CAN-12-4704

Chen, I. X., Chauhan, V. P., Posada, J., Ng, M. R., Wu, M. W., Adstamongkonkul, P., et al. (2019). Blocking CXCR4 alleviates desmoplasia, increases T-lymphocyte infiltration, and improves immunotherapy in metastatic breast cancer, Proc. Natl. Acad. Sci. U.S.A. 116, 4558-4566. doi:10.1073/ pnas. 1815515116

Chen, J., Chang, H., Peng, X., Gu, Y., Yi, L., Zhang, Q., et al. (2016). 3,6dihydroxyflavone suppresses the epithelial-mesenchymal transition in breast cancer cells by inhibiting the Notch signaling pathway. Sci. Rep. 6, 28858. doi:10.1038/srep28858

Chen, L., He, J., Zhou, J., Xiao, Z., Ding, N., Duan, Y., et al. (2019a). EIF2A promotes cell survival during paclitaxel treatment in vitro and in vivo, J. Cell Mol. Med. 23, 6060-6071. doi:10.1111/jcmm.14469

Chen, L., Yang, G., and Dong, H. (2019b). Everolimus reverses palbociclib resistance in ER+ human breast cancer cells by inhibiting phosphatidylinositol 3-kinase(PI3K)/Akt/Mammalian target of rapamycin (mTOR) pathway. Med. Sci. Mon. 25, 77-86. doi:10.12659/msm.912929

Chihara, Y., Shimoda, M., Hori, A., Ohara, A., Naoi, Y., Ikeda, J. I., et al. (2017). A small-molecule inhibitor of SMAD3 attenuates resistance to anti-HER2 drugs in HER2-positive breast cancer cells. Breast Cancer Res. Treat. 166, 55-68. doi:10.1007/s10549-017-4382-6

Cho, Y., Lee, H. W., Kang, H. G., Kim, H. Y., Kim, S. J., and Chun, K. H (2015). Cleaved CD44 intracellular domain supports activation of stemness factors and promotes tumorigenesis of breast cancer. Oncotarget 6, 8709-8721. doi:10. 18632/oncotarget. 3325

Choi, H. J., Jin, S., Cho, H., Won, H. Y., An, H. W., Jeong, G. Y., et al. (2019). CDK12 drives breast tumor initiation and trastuzumab resistance via WNT and IRS1-ErbB-PI3K signaling. EMBO Rep. 20, e48058. doi:10.15252/embr. 201948058

Chien, A. J., Tripathy, D., Albain, K. S., Symmans, W. F., Rugo, H. S., Melisko, M. E., et al. (2019). MK-2206 and standard neoadjuvant chemotherapy improves response in patients with human epidermal growth factor receptor 2-positive and/or hormone receptor-negative breast cancers in the I-spy 2 trial. J. Clin. Oncol. 38, 1059-1069. doi:10.1200/JCO.19.01027

Chung, S. S., Giehl, N., Wu, Y., and Vadgama, J. V. (2014). STAT3 activation in HER2-overexpressing breast cancer promotes epithelial-mesenchymal transition and cancer stem cell traits. Int. J. Oncol. 44, 403-411. doi:10. 3892/ijo.2013.2195

Cidado, J., and Park, B. H. (2012). Targeting the PI3K/Akt/mTOR pathway for breast cancer therapy. J. Mammary Gland Biol. Neoplasia 17, 205-216. doi:10. 1007/s10911-012-9264-2

Clarke, M. F., Dick, J. E., Dirks, P. B., Eaves, C. J., Jamieson, C. H., Jones, D. L., et al. (2006). Cancer stem cells-perspectives on current status and future directions: AACR Workshop on cancer stem cells. Cancer Res 66, 9339-9344. doi:10.1158/ 0008-5472.CAN-06-3126

Cojoc, M., Mabert, K., Muders, M. H., and Dubrovska, A. (2015). A role for cancer stem cells in therapy resistance: cellular and molecular mechanisms. Semin. Cancer Biol. 31, 16-27. doi:10.1016/j.semcancer.2014.06.004

Creighton, C. J., Li, X., Landis, M., Dixon, J. M., Neumeister, V. M., Sjolund, A., et al. (2009). Residual breast cancers after conventional therapy display mesenchymal as well as tumor-initiating features. Proc. Natl. Acad. Sci. U.S.A. 106, 13820-13825. doi:10.1073/pnas.0905718106

Croker, A. K., Goodale, D., Chu, J., Postenka, C., Hedley, B. D., Hess, D. A., et al. (2009). High aldehyde dehydrogenase and expression of cancer stem cell markers selects for breast cancer cells with enhanced malignant and metastatic ability. J. Cell Mol. Med. 13, 2236-2252. doi:10.1111/j.1582-4934. 2008.00455.x
Croker, A. K., and Allan, A. L. (2012). Inhibition of aldehyde dehydrogenase (ALDH) activity reduces chemotherapy and radiation resistance of stem-like ALDHhiCD $44^{+}$human breast cancer cells. Breast Cancer Res. Treat. 133, 75-87. doi:10.1007/s10549-011-1692-y

Cui, J., Hollmen, M., Li, L., Chen, Y., Proulx, S. T., Reker, D., et al. (2017). New use of an old drug: inhibition of breast cancer stem cells by benztropine mesylate. Oncotarget 8, 1007-1022. doi:10.18632/oncotarget.13537

Dave, B., Migliaccio, I., Gutierrez, M. C., Wu, M. F., Chamness, G. C., Wong, H., et al. (2011). Loss of phosphatase and tensin homolog or phosphoinositol-3 kinase activation and response to trastuzumab or lapatinib in human epidermal growth factor receptor 2-overexpressing locally advanced breast cancers. J. Clin. Oncol. 29, 166-173. doi:10.1200/JCO.2009.27.7814

Dean, M. (2009). ABC transporters, drug resistance, and cancer stem cells. J. Mammary Gland Biol. Neoplasia 14, 3-9. doi:10.1007/s10911-009-9109-9

Deng, L., Shang, L., Bai, S., Chen, J., He, X., Martin-Trevino, R., et al. (2014). MicroRNA100 inhibits self-renewal of breast cancer stem-like cells and breast tumor development. Cancer Res. 74, 6648-6660. doi:10.1158/0008-5472.CAN$13-3710$

De Cola, A., Volpe, S., Budani, M. C., Ferracin, M., Lattanzio, R., Turdo, A., et al. (2015). miR-205-5p-mediated downregulation of ErbB/HER receptors in breast cancer stem cells results in targeted therapy resistance. Cell Death Dis. 6, e1823. doi:10.1038/cddis.2015.192

De Luca, A., Fiorillo, M., Peiris-Pages, M., Ozsvari, B., Smith, D. L., SanchezAlvarez, R., et al. (2015). Mitochondrial biogenesis is required for the anchorage-independent survival and propagation of stem-like cancer cells. Oncotarget 6, 14777-14795. doi:10.18632/oncotarget.4401

DeSantis, C. E., Ma, J., Gaudet, M. M., Newman, L. A., Miller, K. D., Goding Sauer, A., et al. (2019). Breast cancer statistics, 2019. CA Cancer J. Clin. 69, 438-451. doi: $10.3322 /$ caac. 21583

Deshmukh, A., Deshpande, K., Arfuso, F., Newsholme, P., and Dharmarajan, A. (2016). Cancer stem cell metabolism: a potential target for cancer therapy. Mol. Cancer 15, 69. doi:10.1186/s12943-016-0555-x

Dey, P., Rathod, M., and De, A. (2019). Targeting stem cells in the realm of drugresistant breast cancer. Breast Cancer (Dove Med Press) 11, 115-135. doi:10. 2147/BCTT.S189224

Diehn, M., Cho, R. W., Lobo, N. A., Kalisky, T., Dorie, M. J., Kulp, A. N., et al. (2009). Association of reactive oxygen species levels and radioresistance in cancer stem cells. Nature 458, 780-783. doi:10.1038/nature07733

Dowsett, M., Nicholson, R. I., and Pietras, R. J. (2005). Biological characteristics of the pure antiestrogen fulvestrant: overcoming endocrine resistance. Breast Cancer Res. Treat. 93 (Suppl. 1), S11-S18. doi:10.1007/s10549-005-9037-3

Droog, M., Beelen, K., Linn, S., and Zwart, W., Tamoxifen resistance: from bench to bedside, Eur. J. Pharmacol., 717 (2013) 47-57. doi:10.1016/j.ejphar.2012.11.071

Dubrovska, A., Hartung, A., Bouchez, L. C., Walker, J. R., Reddy, V. A., Cho, C. Y., et al. (2012). CXCR4 activation maintains a stem cell population in tamoxifenresistant breast cancer cells through AhR signalling. Br. J. Cancer 107, 43-52. doi:10.1038/bjc.2012.105

Du, R., Liu, B., Zhou, L., Wang, D., He, X., Xu, X., et al. (2018). Downregulation of annexin $\mathrm{A} 3$ inhibits tumor metastasis and decreases drug resistance in breast cancer. Cell Death Dis. 9, 126. doi:10.1038/s41419-017-0143-z

Eiro, N., Gonzalez, L. O., Fraile, M., Cid, S., Schneider, J., and Vizoso, F. J. (2019). Breast cancer tumor stroma: cellular components, phenotypic heterogeneity, intercellular communication, prognostic implications and therapeutic opportunities. Cancers 11, 11. doi:10.3390/cancers11050664

Fan, L., Li, F., Zhang, H., Wang, Y., Cheng, C., Li, X., et al. (2010). Co-delivery of PDTC and doxorubicin by multifunctional micellar nanoparticles to achieve active targeted drug delivery and overcome multidrug resistance. Biomaterials 31, 5634-5642. doi:10.1016/j.biomaterials.2010.03.066

Fan, M., Yan, P. S., Hartman-Frey, C., Chen, L., Paik, H., Oyer, S. L., et al. (2006). Diverse gene expression and DNA methylation profiles correlate with differential adaptation of breast cancer cells to the antiestrogens tamoxifen and fulvestrant. Cancer Res. 66, 11954-11966. doi:10.1158/0008-5472.CAN-061666

Farahmand, L., Mansouri, S., Jafarbeik-Iravani, N., Teymourzadeh, A., and Majidzadeh, A. K. (2018). Stemness phenotype in tamoxifen resistant breast cancer cells may be induced by interactions between receptor tyrosine kinases and ERalpha-66, Recent Pat. Anti-Cancer Drug Discov. 13, 302-307. doi:10. 2174/1574892813666180305164634 
Fedier, A., Schwarz, V. A., Walt, H., Carpini, R. D., Haller, U., and Fink, D. (2001). Resistance to topoisomerase poisons due to loss of DNA mismatch repair. Int. J. Cancer 93, 571-576. doi:10.1002/ijc.1356

Fessler, S. P., Wotkowicz, M. T., Mahanta, S. K., and Bamdad, C. (2009). $\mathrm{MUCl}^{*}$ is a determinant of trastuzumab (Herceptin) resistance in breast cancer cells. Breast Cancer Res. Treat. 118, 113-124. doi:10.1007/s10549009-0412-3

Francis, P. A., Regan, M. M., Fleming, G. F., Láng, I., Ciruelos, E., Bellet, M., et al. (2015). Adjuvant ovarian suppression in premenopausal breast cancer. N. Engl. J. Med. 372, 436-446. doi:10.1056/NEJMoa1412379

Frasor, J., Stossi, F., Danes, J. M., Komm, B., Lyttle, C. R., and Katzenellenbogen, B. S. (2004). Selective estrogen receptor modulators: discrimination of agonistic versus antagonistic activities by gene expression profiling in breast cancer cells. Cancer Res. 64, 1522-1533. doi:10.1158/0008-5472.can-03-3326

Gaio, E., Conte, C., Esposito, D., Reddi, E., Quaglia, F., and Moret, F. (2020). CD44 targeting mediated by polymeric nanoparticles and combination of chlorine TPCS2a-PDT and docetaxel-chemotherapy for efficient killing of breast differentiated and stem cancer cells in vitro. Cancers (Basel) 12, 278. doi:10. $3390 /$ cancers 12020278

Gallardo, A., Lerma, E., Escuin, D., Tibau, A., Munoz, J., Ojeda, B., et al. (2012). Increased signalling of EGFR and IGF1R, and deregulation of PTEN/PI3K/Akt pathway are related with trastuzumab resistance in HER2 breast carcinomas. Br. J. Cancer 106, 1367-1373. doi:10.1038/bjc.2012.85

Gargini, R., Cerliani, J. P., Escoll, M., Anton, I. M., and Wandosell, F. (2015). Cancer stem cell-like phenotype and survival are coordinately regulated by Akt/ FoxO/Bim pathway. Stem Cell. 33, 646-660. doi:10.1002/stem.1904

Gao, R., Li, D., Xun, J., Zhou, W., Li, J., Wang, J., et al. (2018). CD44ICD promotes breast cancer stemness via PFKFB4-mediated glucose metabolism. Theranostics 8, 6248-6262. doi:10.7150/thno.28721

Ge, G., Zhou, C., Ren, Y., Tang, X., Wang, K., Zhang, W., et al. (2016). Enhanced SLC34A2 in breast cancer stem cell-like cells induces chemotherapeutic resistance to doxorubicin via SLC34A2-Bmil-ABCC5 signaling. Tumour Biol. 37, 5049-5062. doi:10.1007/s13277-015-4226-0

Gelsomino, L., Panza, S., Giordano, C., Barone, I., Gu, G., Spina, E., et al. (2018). Mutations in the estrogen receptor alpha hormone binding domain promote stem cell phenotype through notch activation in breast cancer cell lines. Cancer Lett. 428, 12-20. doi:10.1016/j.canlet.2018.04.023

Generali, D., Berruti, A., Brizzi, M. P., Campo, L., Bonardi, S., Wigfield, S., et al. (2006). Hypoxia-inducible factor-1alpha expression predicts a poor response to primary chemoendocrine therapy and disease-free survival in primary human breast cancer, Clin. Cancer Res. 12, 4562-4568. doi:10.1158/1078-0432.CCR05-2690

Genovese, I., Ilari, A., Assaraf, Y. G., Fazi, F., and Colotti, G. (2017) Not only P-glycoprotein: amplification of the $\mathrm{ABCB} 1$-containing chromosome region $7 \mathrm{q} 21$ confers multidrug resistance upon cancer cells by coordinated overexpression of an assortment of resistance-related proteins. Drug Resist. Updates 32, 23-46. doi:10.1016/j.drup.2017.10.003

Ghatak, S., Misra, S., and Toole, B. P. (2002). Hyaluronan oligosaccharides inhibit anchorage-independent growth of tumor cells by suppressing the phosphoinositide 3-kinase/Akt cell survival pathway. J. Biol. Chem. 277, 38013-38020. doi:10.1074/jbc.M202404200

Giannakakou, P., Sackett, D. L., Kang, Y. K., Zhan, Z., Buters, J. T., Fojo, T., et al. (1997). Paclitaxel-resistant human ovarian cancer cells have mutant betatubulins that exhibit impaired paclitaxel-driven polymerization. J. Biol. Chem. 272, 17118-17125. doi:10.1074/jbc.272.27.17118

Giessrigl, B., Schmidt, W. M., Kalipciyan, M., Jeitler, M., Bilban, M., Gollinger, M., et al. (2013). Fulvestrant induces resistance by modulating GPER and CDK6 expression: implication of methyltransferases, deacetylases and the hSWI/SNF chromatin remodelling complex. Br. J. Cancer 109, 2751-2762. doi:10.1038/bjc. 2013.583

Ginestier, C., Hur, M. H., Charafe-Jauffret, E., Monville, F., Dutcher, J., Brown, M., et al. (2007). ALDH1 is a marker of normal and malignant human mammary stem cells and a predictor of poor clinical outcome. Cell Stem Cell 1, 555-567. doi:10.1016/j.stem.2007.08.014

Ginestier, C., Wicinski, J., Cervera, N., Monville, F., Finetti, P., Bertucci, F., et al. (2009). Retinoid signaling regulates breast cancer stem cell differentiation. Cell Cycle 8, 3297-3302. doi:10.4161/cc.8.20.9761
Ginestier, C., Liu, S., Diebel, M. E., Korkaya, H., Luo, M., Brown, M., et al. (2010). CXCR1 blockade selectively targets human breast cancer stem cells in vitro and in xenografts. J. Clin. Invest. 120, 485-497. doi:10.1172/JCI39397

Gil, M., Seshadri, M., Komorowski, M. P., Abrams, S. I., and Kozbor, D. (2013). Targeting CXCL12/CXCR4 signaling with oncolytic virotherapy disrupts tumor vasculature and inhibits breast cancer metastases. Proc. Natl. Acad. Sci. U.S.A. 110, E1291-E1300. doi:10.1073/pnas.1220580110

Gilani, R. A., Kazi, A. A., Shah, P., Schech, A. J., Chumsri, S., Sabnis, G., et al. The importance of HER2 signaling in the tumor-initiating cell population in aromatase inhibitor-resistant breast cancer, Breast Cancer Res. Treat. 135 (2012) 681-692. doi:10.1007/s10549-012-2148-8

Global Burden of Disease Cancer Collaboration, Fitzmaurice, C., Dicker, D., Pain, A., Hamavid, H., Moradi-Lakeh, M., et al. The global burden of cancer 2013, JAMA Oncol. 1 (2015) 505-527. doi:10.1001/jamaoncol.2015.0735

Goldsberry, W. N., Londono, A., Randall, T. D., Norian, L. A., and Arend, R. C. (2019). A review of the role of Wnt in cancer immunomodulation. Cancers (Basel), 11.

Gottesman, M. M., Fojo, T., and Bates, S. E. (2002). Multidrug resistance in cancer: role of ATP-dependent transporters. Nat. Rev. Cancer 2, 48-58. doi:10.1038/ $\operatorname{nrc706}$

Gu, Z., Lee, R. Y., Skaar, T. C., Bouker, K. B., Welch, J. N., Lu, J., et al. (2002). Association of interferon regulatory factor-1, nucleophosmin, nuclear factorkappaB, and cyclic AMP response element binding with acquired resistance to Faslodex (ICI 182,780). Cancer Res. 62, 3428-3437.

Gwak, J. M., Kim, M., Kim, H. J., Jang, M. H., and Park, S. Y. (2017). Expression of embryonal stem cell transcription factors in breast cancer: Oct4 as an indicator for poor clinical outcome and tamoxifen resistance. Oncotarget 8, 36305-36318. doi:10.18632/oncotarget.16750

Gyorffy, B., Serra, V., Jurchott, K., Abdul-Ghani, R., Garber, M., Stein, U., et al. (2005). Prediction of doxorubicin sensitivity in breast tumors based on gene expression profiles of drug-resistant cell lines correlates with patient survival. Oncogene 24, 7542-7551. doi:10.1038/sj.onc.1208908

Han, M., Liu, M., Wang, Y., Mo, Z., Bi, X., Liu, Z., et al. (2012). Re-expression of miR-21 contributes to migration and invasion by inducing epithelialmesenchymal transition consistent with cancer stem cell characteristics in MCF-7 cells. Mol. Cell. Biochem. 363, 427-436. doi:10.1007/s11010-0111195-5

Harbeck, N., and Gnant, M. (2017). Breast cancer. Lancet 389, 1134-1150. doi:10. 1016/S0140-6736(16)31891-8

Hardt, O., Wild, S., Oerlecke, I., Hofmann, K., Luo, S., Wiencek, Y., et al. (2012). Highly sensitive profiling of CD44+/CD24- breast cancer stem cells by combining global mRNA amplification and next generation sequencing: evidence for a hyperactive PI3K pathway, Cancer Lett. 325, 165-174. doi:10. 1016/j.canlet.2012.06.010

Harrison, H., Simoes, B. M., Rogerson, L., Howell, S. J., Landberg, G., and Clarke, R. B. (2013). Oestrogen increases the activity of oestrogen receptor negative breast cancer stem cells through paracrine EGFR and Notch signalling. Breast Cancer Res. 15, R21. doi:10.1186/bcr3396

Hasanabady, M. H., and Kalalinia, F. (2016). ABCG2 inhibition as a therapeutic approach for overcoming multidrug resistance in cancer. J. Biosci. 41, 313-324. doi:10.1007/s12038-016-9601-5

He, M., Fu, Y., Yan, Y., Xiao, Q., Wu, H., Yao, W., et al. (2015). The Hedgehog signalling pathway mediates drug response of MCF-7 mammosphere cells in breast cancer patients. Clin. Sci. 129, 809-822. doi:10.1042/CS20140592

He, M., Wu, H., Jiang, Q., Liu, Y., Han, L., Yan, Y., et al. (2019). Hypoxia-inducible factor-2alpha directly promotes BCRP expression and mediates the resistance of ovarian cancer stem cells to adriamycin. Mol. Oncol. 13, 403-421. doi:10. 1002/1878-0261.12419

Hikita, S. T., Kosik, K. S., Clegg, D. O., and Bamdad, C. (2008). MUC1* mediates the growth of human pluripotent stem cells. PloS One 3, e3312. doi:10.1371/ journal.pone. 0003312

Hirschmann-Jax, C., Foster, A. E., Wulf, G. G., Nuchtern, J. G., Jax, T. W., Gobel, U., et al. (2004). A distinct "side population" of cells with high drug efflux capacity in human tumor cells. Proc. Natl. Acad. Sci. U.S.A. 101, 14228-14233. doi:10.1073/pnas.0400067101

Hill, A., McFarlane, S., Mulligan, K., Gillespie, H., Draffin, J. E., Trimble, A., et al. (2006). Cortactin underpins CD44-promoted invasion and adhesion of breast 
cancer cells to bone marrow endothelial cells. Oncogene 25, 6079-6091. doi:10. 1038/sj.onc. 1209628

Horwitz, S. B., Lothstein, L., Manfredi, J. J., Mellado, W., Parness, J., Roy, S. N., et al. (1986). Taxol: mechanisms of action and resistance. Ann. N. Y. Acad. Sci., 466, 733-744. doi:10.1111/j.1749-6632.1986.tb38455.x

Hosea, R., Hardiany, N. S., Ohneda, O., and Wanandi, S. I. (2018). Glucosamine decreases the stemness of human $\operatorname{ALDH}(+)$ breast cancer stem cells by inactivating STAT3. Oncol. Lett. 16, 4737-4744. doi:10.3892/ ol.2018.9222

Hosonaga, M., Arima, Y., Sugihara, E., Kohno, N., and Saya, H. (2014). Expression of CD24 is associated with HER2 expression and supports HER2-Akt signaling in HER2-positive breast cancer cells. Cancer Sci. 105, 779-787. doi:10.1111/cas. 12427

Howell, A. (2008). The endocrine prevention of breast cancer, Best Pract. Res. Clin. Endocrinol. Metabol. 22, 615-623. doi:10.1016/j.beem.2008.09.002

Howell, A., and Robertson, J. (1995). Response to a specific antioestrogen (ICI 182780) in tamoxifen-resistant breast cancer. Lancet 345, 29-30. doi:10.1016/ s0140-6736(95)90739-4

Hu, C., Li, H., Li, J., Zhu, Z., Yin, S., Hao, X., et al. (2008). Analysis of ABCG2 expression and side population identifies intrinsic drug efflux in the HCC cell line MHCC-97L and its modulation by Akt signaling. Carcinogenesis 29, 2289-2297. doi:10.1093/carcin/bgn223

Hu, C., Xu, L., Liang, S., Zhang, Z., Zhang, Y., and Zhang, F. (2016), Lentivirusmediated shRNA targeting Nanog inhibits cell proliferation and attenuates cancer stem cell activities in breast cancer. J. Drug Target. 24, 422-432. doi:10. 3109/1061186X.2015.1082567

Hui, M., Cazet, A., Nair, R., Watkins, D. N., O'Toole, S. A., and Swarbrick, A., The Hedgehog signalling pathway in breast development, carcinogenesis and cancer therapy, Breast Cancer Res. 15 (2013) 203. doi:10.1186/bcr3401

Iorio, M. V., Casalini, P., Piovan, C., Di Leva, G., Merlo, A., Triulzi, T., et al. (2009). microRNA-205 regulates HER3 in human breast cancer. Cancer Res. 69, 2195-2200. doi:10.1158/0008-5472.CAN-08-2920

Ishikawa, T., Utoh, M., Sawada, N., Nishida, M., Fukase, Y., Sekiguchi, F., et al. (1998). Tumor selective delivery of 5 -fluorouracil by capecitabine, a new oral fluoropyrimidine carbamate, in human cancer xenografts. Biochem. Pharmacol. 55, 1091-1097. doi:10.1016/s0006-2952(97)00682-5

Jang, G. B., Hong, I. S., Kim, R. J., Lee, S. Y., Park, S. J., Lee, E. S., et al. (2015). Wnt/ $\beta$-Catenin small-molecule inhibitor CWP232228 preferentially inhibits the growth of breast cancer stem-like cells. Cancer Res. 75, 1691-1702. doi:10. 1158/0008-5472.CAN-14-2041

Jia, D., Tan, Y., Liu, H., Ooi, S., Li, L., Wright, K., et al. (2016). Cardamonin reduces chemotherapy-enriched breast cancer stem-like cells in vitro and in vivo. Oncotarget 7, 771-785. doi:10.18632/oncotarget.5819

Jiang, J., Li, H., Qaed, E., Zhang, J., Song, Y., Wu, R., et al. (2018). Salinomycin, as an autophagy modulator-- a new avenue to anticancer: a review. J. Exp. Clin. Cancer Res. 37, 26. doi:10.1186/s13046-018-0680-z

Jin, X., Jin, X., and Kim, H. (2017). Cancer stem cells and differentiation therapy. Tumour Biol. 39, 1010428317729933. doi:10.1177/1010428317729933

Kazi, A. A., Gilani, R. A., Schech, A. J., Chumsri, S., Sabnis, G., Shah, P., et al. (2014). Nonhypoxic regulation and role of hypoxia-inducible factor 1 in aromatase inhibitor resistant breast cancer. Breast Cancer Res. 16, R15. doi:10.1186/bcr3609

Kettner, N. M., Vijayaraghavan, S., Durak, M. G., Bui, T., Kohansal, M., Ha, M. J., et al. (2019). Combined inhibition of STAT3 and DNA repair in palbociclibresistant ER-positive breast cancer. Clin. Cancer Res. 25, 3996-4013. doi:10. 1158/1078-0432.CCR-18-3274

Kim, S. H., and Singh, S. V. (2014). Mammary cancer chemoprevention by withaferin $\mathrm{A}$ is accompanied by in vivo suppression of self-renewal of cancer stem cells. Cancer Prev. Res. 7, 738-747. doi:10.1158/1940-6207. CAPR-13-0445

Koninki, K., Barok, M., Tanner, M., Staff, S., Pitkanen, J., Hemmila, P., et al. (2010). Multiple molecular mechanisms underlying trastuzumab and lapatinib resistance in JIMT-1 breast cancer cells. Cancer Lett. 294, 211-219. doi:10. 1016/j.canlet.2010.02.002

Koike, Y., Ohta, Y., Saitoh, W., Yamashita, T., Kanomata, N., Moriya, T., et al. (2017). Anti-cell growth and anti-cancer stem cell activities of the noncanonical hedgehog inhibitor GANT61 in triple-negative breast cancer cells. Breast Cancer 24, 683-693. doi:10.1007/s12282-017-0757-0
Kolev, V. N., Wright, Q. G., Vidal, C. M., Ring, J. E., Shapiro, I. M., Ricono, J., et al. (2015). PI3K/mTOR dual inhibitor VS-5584 preferentially targets cancer stem cells, Cancer Res. 75, 446-455. doi:10.1158/0008-5472.CAN-14-1223

Kopp, A., Jonat, W., Schmahl, M., and Knabbe, C. (1995). Transforming growth factor beta 2 (TGF-beta 2) levels in plasma of patients with metastatic breast cancer treated with tamoxifen. Cancer Res. 55, 4512-4515.

Korkaya, H., Paulson, A., Charafe-Jauffret, E., Ginestier, C., Brown, M., Dutcher, J., et al. Regulation of mammary stem/progenitor cells by PTEN/Akt/beta-catenin signaling. PLoS Biol. 7, e1000121 (2009). doi:10.1371/journal.pbio.1000121

Korkaya, H., Kim, G. I., Davis, A., Malik, F., Henry, N. L., Ithimakin, S., et al. (2012). Activation of an IL6 inflammatory loop mediates trastuzumab resistance in HER2+ breast cancer by expanding the cancer stem cell population. Mol. Cell 47, 570-584. doi:10.1016/j.molcel.2012.06.014

Koury, J., Zhong, L., and Hao, J. (2017). Targeting signaling pathways in cancer stem cells for cancer treatment. Stem Cell. Int. 2017 2925869. doi:10.1155/2017/ 2925869

Kubo, M., Nakamura, M., Tasaki, A., Yamanaka, N., Nakashima, H., Nomura, M., et al. (2004). Hedgehog signaling pathway is a new therapeutic target for patients with breast cancer. Cancer Res. 64, 6071-6074. doi:10.1158/0008-5472. CAN-04-0416

Lathan, B., and Von Hoff, D. D. (1984). Cytotoxic activity of echinomycin in a human tumor cloning system. Cancer Drug Deliv. 1, 191-198. doi:10.1089/cdd. 1984.1.191

Latorre, E., Carelli, S., Raimondi, I., D’Agostino, V., Castiglioni, I., Zucal, C., et al. The ribonucleic complex HuR-MALAT1 represses CD133 expression and suppresses epithelial-mesenchymal transition in breast cancer, Cancer Res. 76 (2016) 2626-2636. doi:10.1158/0008-5472.CAN-15-2018

Leccia, F., Del Vecchio, L., Mariotti, E., Di Noto, R., Morel, A. P., Puisieux, A., et al. (2014). ABCG2, a novel antigen to sort luminal progenitors of BRCA1- breast cancer cells. Mol. Cancer 13, 213. doi:10.1186/1476-4598-13-213

Lee, E., Nichols, P., Spicer, D., Groshen, S., Yu, M. C., and Lee, A. S. (2006). GRP78 as a novel predictor of responsiveness to chemotherapy in breast cancer. Cancer Res. 66, 7849-7853. doi:10.1158/0008-5472.CAN-06-1660

Lee, K. M., Giltnane, J. M., Balko, J. M., Schwarz, L. J., Guerrero-Zotano, A. L., Hutchinson, K. E., et al. (2017). MYC and MCL1 cooperatively promote chemotherapy-resistant breast cancer stem cells via regulation of mitochondrial oxidative phosphorylation, Cell Metabol. 26, 633-647.e7. doi:10.1016/j.cmet.2017.09.009

Li, Y., Xian, M., Yang, B., Ying, M., and He, Q. (2017). Inhibition of KLF4 by statins reverses adriamycin-induced metastasis and cancer stemness in Osteosarcoma cells, Stem Cell Rep. 8, 1617-1629. doi:10.1016/j.stemcr.2017.04.025

Li, Y., Zhang, T., Korkaya, H., Liu, S., Lee, H. F., Newman, B., et al. (2010). Sulforaphane, a dietary component of broccoli/broccoli sprouts, inhibits breast cancer stem cells. Clin. Cancer Res. 16, 2580-2590. doi:10.1158/1078-0432. CCR-09-2937

Li, C. Y., Miao, K. L., Chen, Y., Liu, L. Y., Zhao, G. B., Lin, M. H., et al. (2018). Jagged 2 promotes cancer stem cell properties of triple negative breast cancer cells and paclitaxel resistance via regulating microRNA-200. Eur. Rev. Med. Pharmacol. Sci., 22, 6008-6014. doi:10.26355/eurrev_201809_15936

Li, Y. W., Xu, J., Zhu, G. Y., Huang, Z. J., Lu, Y., Li, X. Q., et al. (2018). Apigenin suppresses the stem cell-like properties of triple-negative breast cancer cells by inhibiting YAP/TAZ activity. Cell Death Dis. 4, 105. doi:10.1038/s41420-0180124-8

Li, S., Fan, Y., Kumagai, A., Kawakita, E., Kitada, M., Kanasaki, K., et al. (2020). Deficiency in dipeptidyl peptidase-4 promotes chemoresistance through the CXCL12/CXCR4/mTOR/TGFbeta signaling pathway in breast cancer cells. Int. J. Mol. Sci. 21, 805. doi:10.3390/ijms21030805

Li, S. Y., Sun, R., Wang, H. X., Shen, S., Liu, Y., Du, X. J., et al. (2015). Combination therapy with epigenetic-targeted and chemotherapeutic drugs delivered by nanoparticles to enhance the chemotherapy response and overcome resistance by breast cancer stem cells. J. Contr. Release 205, 7-14. doi:10. 1016/j.jconrel.2014.11.011

Liang, Y. J., Wang, C. Y., Wang, I. A., Chen, Y. W., Li, L. T., Lin, C. Y., et al. (2017). Interaction of glycosphingolipids GD3 and GD2 with growth factor receptors maintains breast cancer stem cell phenotype. Oncotarget. 8, 47454-47473. doi:10.18632/oncotarget.17665

Liapis, V., Zinonos, I., Labrinidis, A., Hay, S., Ponomarev, V., Panagopoulos, V., et al. (2016). Anticancer efficacy of the hypoxia-activated prodrug evofosfamide 
(TH-302) in osteolytic breast cancer murine models. Cancer Med. 5, 534-545. doi:10.1002/cam4.599

Lillo, M. A., Nichols, C., Perry, C., Runke, S., Krutilina, R., Seagroves, T. N., et al. (2017). Methylparaben stimulates tumor initiating cells in ER+ breast cancer models, J. Appl. Toxicol. 37, 417-425. doi:10.1002/jat.3374

Liu, C., Xing, H., Guo, C., Yang, Z., Wang, Y., and Wang, Y. (2019). MiR-124 reversed the doxorubicin resistance of breast cancer stem cells through STAT3/ HIF-1 signaling pathways. Cell Cycle 18, 2215-2227. doi:10.1080/15384101. 2019.1638182

Liu, J., Ye, Z., Xiang, M., Chang, B., Cui, J., Ji, T., et al. (2019). Functional extracellular vesicles engineered with lipid-grafted hyaluronic acid effectively reverse cancer drug resistance. Biomaterials 223, 119475. doi:10.1016/j. biomaterials.2019.119475

Liu, Y., Zhang, X. B., Liu, J. J., Zhang, S., and Zhang, J. (2019). [NVP-BKM120 in combination with letrozole inhibit human breast cancer stem cells via PI3K/ mTOR pathway]. Zhonghua Yixue Zazhi 99, 1075-1080. doi:10.3760/cma.j. issn.0376-2491.2019.14.008

Liu, L., Yang, M., Kang, R., Wang, Z., Zhao, Y., Yu, Y., et al. (2011). DAMPmediated autophagy contributes to drug resistance. Autophagy 7, 112-114. doi:10.4161/auto.7.1.14005

Liu, T. J., Sun, B. C., Zhao, X. L., Zhao, X. M., Sun, T., Gu, Q., et al. (2013). CD133+ cells with cancer stem cell characteristics associates with vasculogenic mimicry in triple-negative breast cancer. Oncogene 32, 544-553. doi:10.1038/onc.2012.85

Liu, Y., Zhang, X., Liu, J., Hou, G., Zhang, S., and Zhang, J. (2014). Everolimus in combination with letrozole inhibit human breast cancer MCF-7/Aro stem cells via PI3K/mTOR pathway: an experimental study, Tumour Biol. 35, 1275-1286. doi:10.1007/s13277-013-1170-8

Liu, Y., Yu, C., Wu, Y., Sun, X., Su, Q., You, C., et al. (2017). CD44. J. Cell Mol. Med. 21, 1979-1988. doi:10.1111/jcmm.13118

Liu, B. Q., Zhang, S., Li, S., An, M. X., Li, C., Yan, J., et al. (2017). BAG3 promotes stem cell-like phenotype in breast cancer by upregulation of CXCR4 via interaction with its transcript. Cell Death Dis. 8, e2933. doi:10.1038/cddis. 2017.324

Liu, Z., Bandyopadhyay, A., Nichols, R. W., Wang, L., Hinck, A. P., Wang, S., et al. (2012). Blockade of autocrine TGF-beta signaling inhibits stem cell phenotype, survival, and metastasis of murine breast cancer cells, J. Stem Cell Res. Ther. 2, 1-8. doi:10.4172/2157-7633.1000116

Locatelli, M. A., Aftimos, P., Dees, E. C., LoRusso, P. M., Pegram, M. D., Awada, A., et al. (2017). Phase I study of the gamma secretase inhibitor PF-03084014 in combination with docetaxel in patients with advanced triple-negative breast cancer, Oncotarget. 8, 2320-2328. doi:10.18632/oncotarget.13727

Loh, Y. N., Hedditch, E. L., Baker, L. A., Jary, E., Ward, R. L., and Ford, C. E. (2013). The Wnt signalling pathway is upregulated in an in vitro model of acquired tamoxifen resistant breast cancer. BMC Cancer 13, 174. doi:10.1186/1471-2407-13-174

Lombardo, Y., Faronato, M., Filipovic, A., Vircillo, V., Magnani, L., and Coombes, R. C. (2014). Nicastrin and Notch4 drive endocrine therapy resistance and epithelial to mesenchymal transition in MCF7 breast cancer cells. Breast Cancer Res. 16, R62. doi:10.1186/bcr3675

Louderbough, J. M., and Schroeder, J. A. (2011). Understanding the dual nature of CD44 in breast cancer progression. Mol. Cancer Res. 9, 1573-1586. doi:10.1158/ 1541-7786.MCR-11-0156

Luker, K. E., Lewin, S. A., Mihalko, L. A., Schmidt, B. T., Winkler, J. S., Coggins, N. L., et al. (2012). Scavenging of CXCL12 by CXCR7 promotes tumor growth and metastasis of CXCR4-positive breast cancer cells. Oncogene 31, 4750-4758. doi:10.1038/onc.2011.633

Luo, M. L., Gong, C., Chen, C. H., Hu, H., Huang, P., Zheng, M., et al. (2015). The Rab2A GTPase promotes breast cancer stem cells and tumorigenesis via Erk signaling activation. Cell Rep. 11, 111-124. doi:10.1016/j.celrep.2015.03.002

Lv, Y., Xu, C., Zhao, X., Lin, C., Yang, X., Xin, X., et al. (2018a). Nanoplatform assembled from a CD44-targeted prodrug and smart liposomes for dual targeting of tumor microenvironment and cancer cells. ACS Nano 12, 1519-1536. doi:10.1021/acsnano.7b08051

Lv, Y., Zhao, X., Zhu, S., Li, S., Xiao, Q., He, W., et al. (2018b). Targeting intracellular MMPs efficiently inhibits tumor metastasis and angiogenesis. Theranostics 8, 2830-2845. doi:10.7150/thno.23209

Lytle, N. K., Barber, A. G., and Reya, T. (2018). Stem cell fate in cancer growth, progression and therapy resistance. Nat. Rev. Cancer 18, 669-680. doi:10.1038/ s41568-018-0056-x
Ma, C. X., Reinert, T., Chmielewska, I., and Ellis, M. J. (2015). Mechanisms of aromatase inhibitor resistance. Nat. Rev. Cancer 15, 261-275. doi:10.1038/ $\operatorname{nrc} 3920$

Ma, R., Karthik, G. M., Lovrot, J., Haglund, F., Rosin, G., Katchy, A., et al. (2017). Estrogen receptor beta as a therapeutic target in breast cancer stem cells. J. Natl. Cancer Inst. 109, 1-14. doi:10.1093/jnci/djw236

Macedo, L. F., Guo, Z., Tilghman, S. L., Sabnis, G. J., Qiu, Y., and Brodie, A. (2006). Role of androgens on MCF-7 breast cancer cell growth and on the inhibitory effect of letrozole. Cancer Res. 66, 7775-7782. doi:10.1158/0008-5472.CAN-05-3984

Magnani, L., Stoeck, A., Zhang, X., Lanczky, A., Mirabella, A. C., Wang, T. L., et al. (2013). Genome-wide reprogramming of the chromatin landscape underlies endocrine therapy resistance in breast cancer. Proc. Natl. Acad. Sci. U.S.A. 110, E1490-E1499. doi:10.1073/pnas.1219992110

Magnani, M., Ortuso, F., Soro, S., Alcaro, S., Tramontano, A., and Botta, M. (2006). The betaI/betaIII-tubulin isoforms and their complexes with antimitotic agents. Docking and molecular dynamics studies. FEBS J. 273, 3301-3310. doi:10.1111/ j.1742-4658.2006.05340.x

Magnifico, A., Albano, L., Campaner, S., Delia, D., Castiglioni, F., Gasparini, P., et al. (2009). Tumor-initiating cells of HER2-positive carcinoma cell lines express the highest oncoprotein levels and are sensitive to trastuzumab. Clin. Cancer Res. 15, 2010-2021. doi:10.1158/1078-0432.CCR-08-1327

Manavathi, B., Dey, O., Gajulapalli, V. N., Bhatia, R. S., Bugide, S., and Kumar, R. (2013). Derailed estrogen signaling and breast cancer: an authentic couple. Endocr. Rev. 34, 1-32. doi:10.1210/er.2011-1057

Manerba, M., Govoni, M., Manet, I., Leale, A., Comparone, A., and Di Stefano, G. (2019). Metabolic activation triggered by cAMP in MCF-7 cells generates lethal vulnerability to combined oxamate/etomoxir. Biochim. Biophys. Acta Gen. Subj. 1863, 1177-1186. doi:10.1016/j.bbagen.2019.04.008

Majumder, M., Xin, X., Liu, L., Tutunea-Fatan, E., Rodriguez-Torres, M., Vincent, K., et al. (2016). COX-2 induces breast cancer stem cells via EP4/PI3K/AKT/ NOTCH/WNT Axis. Stem Cell. 34, 2290-2305. doi:10.1002/stem.2426

Mao, Q., and Unadkat, J. D. (2015). Role of the breast cancer resistance protein (BCRP/ABCG2) in drug transport--an update. AAPS J. 17, 65-82. doi:10.1208/ s12248-014-9668-6

Marcato, P., Dean, C. A., Pan, D., Araslanova, R., Gillis, M., Joshi, M., et al. (2011). Aldehyde dehydrogenase activity of breast cancer stem cells is primarily due to isoform ALDH1A3 and its expression is predictive of metastasis. Stem Cell. 29, 32-45. doi:10.1002/stem.563

Marsden, C. G., Wright, M. J., Pochampally, R., and Rowan, B. G. (2009). Breast tumor-initiating cells isolated from patient core biopsies for study of hormone action. Methods Mol. Biol. 590, 363-375. doi:10.1007/978-1-60327-378-7_23

Martin-Castillo, B., Oliveras-Ferraros, C., Vazquez-Martin, A., Cufi, S., Moreno, J. M., Corominas-Faja, B., et al. (2013). Basal/HER2 breast carcinomas: integrating molecular taxonomy with cancer stem cell dynamics to predict primary resistance to trastuzumab (Herceptin). Cell Cycle 12, 225-245. doi:10.4161/cc.23274

Marotta, L. L., Almendro, V., Marusyk, A., Shipitsin, M., Schemme, J., Walker, S. R., et al. (2011). The JAK2/STAT3 signaling pathway is required for growth of $\mathrm{CD} 44^{+} \mathrm{CD} 24^{-}$stem cell-like breast cancer cells in human tumors. J. Clin. Invest. 121, 2723-2735. doi:10.1172/JCI44745

McCartney, A., Moretti, E., Sanna, G., Pestrin, M., Risi, E., Malorni, L., et al. (2018). The role of abemaciclib in treatment of advanced breast cancer. Ther. Adv. Med. Oncol. 10, 1758835918776925. doi:10.1177/1758835918776925

McClelland, R. A., Barrow, D., Madden, T. A., Dutkowski, C. M., Pamment, J., Knowlden, J. M., et al. (2001). Enhanced epidermal growth factor receptor signaling in MCF7 breast cancer cells after long-term culture in the presence of the pure antiestrogen ICI 182,780 (Faslodex). Endocrinology 142, 2776-2788. doi:10.1210/endo.142.7.8259

Meyer, M. J., Fleming, J. M., Lin, A. F., Hussnain, S. A., Ginsburg, E., and Vonderhaar, B. K. (2010). CD44posCD49fhiCD133/2hi defines xenograftinitiating cells in estrogen receptor-negative breast cancer. Cancer Res. 70, 4624-4633. doi:10.1158/0008-5472.CAN-09-3619

Muller, A., Homey, B., Soto, H., Ge, N., Catron, D., Buchanan, M. E., et al. (2001). Involvement of chemokine receptors in breast cancer metastasis. Nature 410, 50-56. doi:10.1038/35065016

Mohammady, M., Ghetmiri, S. I., Baharizade, M., Morowvat, M. H., and Torabi, S. (2019). Expanding the biotherapeutics realm via miR-34a: "potent clever little" agent in breast cancer therapy. Curr. Pharmaceut. Biotechnol. 20, 665-673. doi:10.2174/1389201020666190617162042 
Mukherjee, P., Gupta, A., Chattopadhyay, D., and Chatterji, U. (2017). Modulation of SOX2 expression delineates an end-point for paclitaxel-effectiveness in breast cancer stem cells. Sci. Rep. 7, 9170. doi:10.1038/s41598-017-08971-2

Mukherjee, S., Manna, A., Bhattacharjee, P., Mazumdar, M., Saha, S., Chakraborty, S., et al. (2016). Non-migratory tumorigenic intrinsic cancer stem cells ensure breast cancer metastasis by generation of CXCR4 $(+)$ migrating cancer stem cells, Oncogene, 35, 4937-4948. doi:10.1038/onc.2016.26

Muntimadugu, E., Kumar, R., Saladi, S., Rafeeqi, T. A., and Khan, W. (2016). CD44 targeted chemotherapy for co-eradication of breast cancer stem cells and cancer cells using polymeric nanoparticles of salinomycin and paclitaxel. Colloids Surf. B Biointerfaces 143, 532-546. doi:10.1016/j.colsurfb.2016.03.075

Munz, M., Baeuerle, P. A., and Gires, O. (2009). The emerging role of EpCAM in cancer and stem cell signaling, Cancer Res. 69, 5627-5629. doi:10.1158/00085472.CAN-09-0654

Musgrove, E. A., and Sutherland, R. L. (2009). Biological determinants of endocrine resistance in breast cancer, Nat. Rev. Cancer, 9, 631-643. doi:10.1038/nrc2713

Muthupandian, S., Barabadi, H., Ramachandran, B., Venkatraman, G., and Ponmurugan, K. (2019). Emerging plant-based anti-cancer green nanomaterials in present scenario. Compr. Anal. Chem. 87, 291-318. doi:10. 1016/bs.coac.2019.09.001

Nalla, L. V., Kalia, K., and Khairnar, A. (2019). Self-renewal signaling pathways in breast cancer stem cells. Int. J. Biochem. Cell Biol. 107,140-153. doi:10.1016/j. biocel.2018.12.017

Nagata, Y., Lan, K. H., Zhou, X., Tan, M., Esteva, F. J., Sahin, A. A., et al. (2004). PTEN activation contributes to tumor inhibition by trastuzumab, and loss of PTEN predicts trastuzumab resistance in patients. Cancer Cell 6, 117-127. doi:10.1016/j.ccr.2004.06.022

Naito, M., Matsuba, Y., Sato, S., Hirata, H., and Tsuruo, T. (2002). MS-209, a quinoline-type reversal agent, potentiates antitumor efficacy of docetaxel in multidrug-resistant solid tumor xenograft models. Clin. Cancer Res. 8, $582-588$

Nasr, M., Farghaly, M., Elsaba, T., El-Mokhtar, M., Radwan, R., Elsabahy, M., et al. (2018). Resistance of primary breast cancer cells with enhanced pluripotency and stem cell activity to sex hormonal stimulation and suppression. Int. J. Biochem. Cell Biol. 105, 84-93. doi:10.1016/j.biocel.2018.10.005

Naor, D., Sionov, R. V., and Ish-Shalom, D. (1997). CD44: structure, function, and association with the malignant process. Adv. Cancer Res. 71, 241-319. doi:10. 1016/s0065-230x(08)60101-3

Nguyen, Y. T., Moon, J. Y., Ediriweera, M. K., and Cho, S. K. (2020). Phenethyl isothiocyanate suppresses stemness in the chemo- and radio-resistant triplenegative breast cancer cell line MDA-MB-231/IR via downregulation of metadheri, Cancers, 12, 268. 10.3390/cancers12020268.

Nicolay, N. H., Ruhle, A., Perez, R. L., Trinh, T., Sisombath, S., Weber, K. J., et al. (2016). Mesenchymal stem cells exhibit resistance to topoisomerase inhibition. Cancer Lett. 374, 75-84. doi:10.1016/j.canlet.2016.02.007

Nourbakhsh, M., Farzaneh, S., Taghikhani, A., Zarghi, A., and Noori, S. (2020). The effect of a newly synthesized ferrocene derivative AGAINST MCF-7 breast cancer cells and spheroid stem cells through ROS production and inhibition of JAK2/STAT3 signaling pathway. Anticancer Agents Med. Chem. 20, 875-886. doi:10.2174/1871520620666200101151743

Ocana, A., Gil-Martin, M., Martin, M., Rojo, F., Antolin, S., Guerrero, A., et al. (2017). A phase I study of the SRC kinase inhibitor dasatinib with trastuzumab and paclitaxel as first line therapy for patients with HER2-overexpressing advanced breast cancer. Oncotarget 8, 73144-73153. doi:10.18632/ oncotarget. 17113

Ohlfest, J. R., Zellmer, D. M., Panyam, J., Swaminathan, S. K., Oh, S., Waldron, N. N., et al. (2013). Immunotoxin targeting CD133(+) breast carcinoma cells, Drug Deliv. Transl. Res. 3, 195-204. doi:10.1007/s13346-012-0066-2

Ojo, D., Wei, F., Liu, Y., Wang, E., Zhang, H., Lin, X., et al. (2015). Factors promoting tamoxifen resistance in breast cancer via stimulating breast cancer stem cell expansion. Curr. Med. Chem. 22, 2360-2374. doi:10.2174/ 0929867322666150416095744

Oudin, M. J., Barbier, L., Schafer, C., Kosciuk, T., Miller, M. A., Han, S., et al. (2017). MENA confers resistance to paclitaxel in triple-negative breast cancer. Mol. Cancer Ther. 16, 143-155. doi:10.1158/1535-7163.MCT-16-0413

Ouhtit, A., Rizeq, B., Saleh, H. A., Rahman, M. M., and Zayed, H. (2018). Novel CD44-downstream signaling pathways mediating breast tumor invasion. Int. J. Biol. Sci. 14, 1782-1790. doi:10.7150/ijbs.23586
Oskarsson, T., Batlle, E., and Massagué, J. (2014). Metastatic stem cells: sources, niches, and vital pathways. Cell Stem Cell 14, 306-321. doi:10.1016/j.stem.2014. 02.002

O’Toole, S. A., Machalek, D. A., Shearer, R. F., Millar, E. K., Nair, R., Schofield, P., et al. (2011). Hedgehog overexpression is associated with stromal interactions and predicts for poor outcome in breast cancer. Cancer Res. 71, 4002-4014. doi:10.1158/0008-5472.CAN-10-3738

Palomeras, S., Ruiz-Martinez, S., and Puig, T. (2018). Targeting breast cancer stem cells to overcome treatment resistance. Molecules 23, 2193. doi:10.3390/ molecules 23092193

Pandey, K., An, H. J., Kim, S. K., Lee, S. A., Kim, S., Lim, S. M., et al. (2019). Molecular mechanisms of resistance to CDK4/6 inhibitors in breast cancer: a review, Int. J. Cancer 145, 1179-1188. doi:10.1002/ijc.32020

Pece, S., Tosoni, D., Confalonieri, S., Mazzarol, G., Vecchi, M., Ronzoni, S., et al. (2010). Biological and molecular heterogeneity of breast cancers correlates with their cancer stem cell content. Cell 140, 62-73. doi:10.1016/j.cell.2009.12.007

Pelekanou, V., Notas, G., Athanasouli, P., Alexakis, K., Kiagiadaki, F., Peroulis, N., et al. (2018). BCMA (TNFRSF17) induces APRIL and BAFF mediated breast cancer cell stemness Front. Oncol. 8, 301. doi:10.3389/fonc.2018.00301

Pena-Solorzano, D., Stark, S. A., Konig, B., Sierra, C. A., and Ochoa-Puentes, C., ABCG2/BCRP: specific and nonspecific modulators. Med. Res. Rev., 37 (2017) 987-1050. doi:10.1002/med.21428

Phillips, T. M., McBride, W. H., and Pajonk, F. (2006). The response of CD24(-/ low)/CD44+ breast cancer-initiating cells to radiation. J. Natl. Cancer Inst. 98, 1777-1785. doi:10.1093/jnci/djj495

Piva, M., Domenici, G., Iriondo, O., Rabano, M., Simoes, B. M., Comaills, V., et al. (2014). Sox2 promotes tamoxifen resistance in breast cancer cells. EMBO Mol. Med. 6, 66-79. doi:10.1002/emmm.201303411

Ponta, H., Sherman, L., and Herrlich, P. A. (2003). CD44: from adhesion molecules to signalling regulators. Nat. Rev. Mol. Cell Biol. 4, 33-45. doi:10.1038/nrm1004

Ponti, D., Costa, A., Zaffaroni, N., Pratesi, G., Petrangolini, G., Coradini, D., et al. (2005). Isolation and in vitro propagation of tumorigenic breast cancer cells with stem/progenitor cell properties. Cancer Res. 65, 5506-5511. doi:10.1158/ 0008-5472.CAN-05-0626

Posada, I. M. D., Lectez, B., Sharma, M., Oetken-Lindholm, C., Yetukuri, L., Zhou, Y., et al. (2017). Rapalogs can promote cancer cell stemness in vitro in a Galectin-1 and H-ras-dependent manner, Oncotarget, 8, 44550-44566. doi:10. 18632/oncotarget. 17819

Press, M. F., Sauter, G., Buyse, M., Bernstein, L., Guzman, R., Santiago, A., et al. (2011). Alteration of topoisomerase II-alpha gene in human breast cancer: association with responsiveness to anthracycline-based chemotherapy. J. Clin. Oncol. 29, 859-867. doi:10.1200/JCO.2009.27.5644

Raffo, D., Berardi, D. E., Pontiggia, O., Todaro, L., de Kier Joffe, E. B., and Simian, M. (2013). Tamoxifen selects for breast cancer cells with mammosphere forming capacity and increased growth rate. Breast Cancer Res. Treat. 142, 537-548. doi:10.1007/s10549-013-2760-2

Ramaswamy, B., Lu, Y., Teng, K. Y., Nuovo, G., Li, X., Shapiro, C. L., et al. (2012). Hedgehog signaling is a novel therapeutic target in tamoxifen-resistant breast cancer aberrantly activated by PI3K/AKT pathway. Cancer Res. 72, 5048-5059. doi:10.1158/0008-5472.CAN-12-1248

Real, P. J., and Ferrando, A. A. (2009). NOTCH inhibition and glucocorticoid therapy in T-cell acute lymphoblastic leukemia. Leukemia 23, 1374-1377. doi:10.1038/leu.2009.75

Rebucci, M., and Michiels, C. (2013). Molecular aspects of cancer cell resistance to chemotherapy. Biochem. Pharmacol. 85, 1219-1226. doi:10.1016/j.bcp.2013.02.017

Reya, T., Morrison, S. J., Clarke, M. F., and Weissman, I. L. (2001). Stem cells, cancer, and cancer stem cells. Nature 414, 105-111. doi:10.1038/35102167

Rhodes, L. V., Muir, S. E., Elliott, S., Guillot, L. M., Antoon, J. W., Penfornis, P., et al. (2010). Adult human mesenchymal stem cells enhance breast tumorigenesis and promote hormone independence. Breast Cancer Res. Treat. 121, 293-300. doi:10.1007/s10549-009-0458-2

Robey, R. W., Pluchino, K. M., Hall, M. D., Fojo, A. T., Bates, S. E., and Gottesman, M. M. (2018). Revisiting the role of ABC transporters in multidrug-resistant cancer. Nat. Rev. Cancer 18, 452-464. doi:10.1038/s41568-018-0005-8

Rodriguez, D., Ramkairsingh, M., Lin, X., Kapoor, A., Major, P., and Tang, D. (2019). The central contributions of breast cancer stem cells in developing resistance to endocrine therapy in estrogen receptor (ER)-Positive breast cancer. Cancers (Basel) 11, 1028. doi:10.3390/cancers11071028 
Roscigno, G., Quintavalle, C., Donnarumma, E., Puoti, I., Diaz-Lagares, A., Iaboni, M., et al. (2016). MiR-221 promotes stemness of breast cancer cells by targeting DNMT3b. Oncotarget 7, 580-592. doi:10.18632/oncotarget.5979

Saeki, T., Nomizum, T., Toi, M., Ito, Y., Noguchi, S., Kobayashi, T., et al. (2007). Dofequidar fumarate (MS-209) in combination with cyclophosphamide, doxorubicin, and fluorouracil for patients with advanced or recurrent breast cancer. J. Clin. Oncol. 25, 411-417. doi:10.1200/JCO.2006.08.1646

Samanta, D., Gilkes, D. M., Chaturvedi, P., Xiang, L., and Semenza, G. L. (2014). Hypoxia-inducible factors are required for chemotherapy resistance of breast cancer stem cells. Proc. Natl. Acad. Sci. U.S.A. 111, E5429-E5438. doi:10.1073/ pnas. 1421438111

Sand, A., Piacsek, M., Donohoe, D. L., Duffin, A. T., Riddell, G. T., Sun, C., et al. (2020). WEE1 inhibitor, AZD1775, overcomes trastuzumab resistance by targeting cancer stem-like properties in HER2-positive breast cancer. Cancer Lett. 472, 119-131. doi:10.1016/j.canlet.2019.12.023

Sansone, P., Ceccarelli, C., Berishaj, M., Chang, Q., Rajasekhar, V. K., Perna, F., et al. (2016). Self-renewal of CD133(hi) cells by IL6/Notch3 signalling regulates endocrine resistance in metastatic breast cancer. Nat. Commun. 7, 10442. doi:10.1038/ncomms10442

Sarkar, A., Chanda, A., Regmi, S. C., Karve, K., Deng, L., Jay, G. D., et al. (2019). Recombinant human PRG4 (rhPRG4) suppresses breast cancer cell invasion by inhibiting TGFbeta-Hyaluronan-CD44 signalling pathway. PLoS One 14, e0219697. doi:10.1371/journal.pone.0219697

Saravanan, M., Vahidi, H., Cruz, D. M., Vernet-Crua, A., and Barabadi, H. (2020). Emerging antineoplastic biogenic gold nanomaterials for breast cancer therapeutics: a systematic review. Int. J. Nanomed. 15, 3577-3595. doi:10. 2147/IJN.S240293

Scatena, C., Roncella, M., Di Paolo, A., Aretini, P., Menicagli, M., Fanelli, G., et al. (2018). Doxycycline, an inhibitor of mitochondrial biogenesis, effectively reduces cancer stem cells (CSCs) in early breast cancer patients: a clinical pilot study. Front. Oncol. 8, 452. doi:10.3389/fonc.2018.00452

Schaffner, F., Yokota, N., Carneiro-Lobo, T., Kitano, M., Schaffer, M., Anderson, G. M., et al. (2013). Endothelial protein $C$ receptor function in murine and human breast cancer development. PLoS One 8, e61071. doi:10.1371/journal.pone. 0061071

Schott, A. F., Landis, M. D., Dontu, G., Griffith, K. A., Layman, R. M., Krop, I., et al. (2013). Preclinical and clinical studies of gamma secretase inhibitors with docetaxel on human breast tumors. Clin. Cancer Res. 19, 1512-1524. doi:10. 1158/1078-0432.CCR-11-3326

Semenza, G. L. (2015). Regulation of the breast cancer stem cell phenotype by hypoxia-inducible factors. Clin. Sci. 129, 1037-1045. doi:10.1042/CS20150451

Sena, L. A., and Chandel, N. S. (2012). Physiological roles of mitochondrial reactive oxygen species. Mol. Cell 48, 158-167. doi:10.1016/j.molcel.2012.09.025

Seo, A. N., Lee, H. J., Kim, E. J., Jang, M. H., Kim, Y. J., Kim, J. H., et al. (2016). Expression of breast cancer stem cell markers as predictors of prognosis and response to trastuzumab in HER2-positive breast cancer. Br. J. Cancer 114, 1109-1116. doi:10.1038/bjc.2016.101

Shi, H., Zhang, W., Zhi, Q., and Jiang, M. (2016). Lapatinib resistance in HER2+ cancers: latest findings and new concepts on molecular mechanisms. Tumour Biol. 37, 15411-15431. doi:10.1007/s13277-016-5467-2

Shan, N. L., Wahler, J., Lee, H. J., Bak, M. J., Gupta, S. D., Maehr, H., et al. (2017). Vitamin D compounds inhibit cancer stem-like cells and induce differentiation in triple negative breast cancer. J. Steroid Biochem. Mol. Biol. 173, 122-129. doi:10.1016/j.jsbmb.2016.12.001

Shigdar, S., Qiao, L., Zhou, S. F., Xiang, D., Wang, T., Li, Y., et al. (2013). RNA aptamers targeting cancer stem cell marker CD133. Cancer Lett. 330, 84-95. doi:10.1016/j.canlet.2012.11.032

Shim, Y., and Song, J. M. (2015). Quantum dot nanoprobe-based high-content monitoring of notch pathway inhibition of breast cancer stem cell by capsaicin. Mol. Cell. Probes 29, 376-381. doi:10.1016/j.mcp.2015.09.004

Shinde, A., Hardy, S. D., Kim, D., Akhand, S. S., Jolly, M. K., Wang, W. H., et al. (2019). Spleen tyrosine kinase-mediated autophagy is required for epithelialmesenchymal plasticity and metastasis in breast cancer. Cancer Res. 79, 1831-1843. doi:10.1158/0008-5472.CAN-18-2636

Si, X., Liu, Y., Lv, J., Ding, H., Zhang, X. A., Shao, L., et al. (2016). ERalpha propelled aberrant global DNA hypermethylation by activating the DNMT1 gene to enhance anticancer drug resistance in human breast cancer cells. Oncotarget 7 , 20966-20980. doi:10.18632/oncotarget.8038
Siegel, R. L., Miller, K. D., and Jemal, A. (2019). Cancer statistics, 2019. CA Cancer J. Clin. 69, 7-34. doi:10.3322/caac.21551

Simoes, B. M., O’Brien, C. S., Eyre, R., Silva, A., Yu, L., Sarmiento-Castro, A., et al. (2015). Anti-estrogen resistance in human breast tumors is driven by JAG1NOTCH4-dependent cancer stem cell activity. Cell Rep. 12, 1968-1977. doi:10. 1016/j.celrep.2015.08.050

Sims-Mourtada, J., Opdenaker, L. M., Davis, J., Arnold, K. M., and Flynn, D. (2015). Taxane-induced hedgehog signaling is linked to expansion of breast cancer stem-like populations after chemotherapy. Mol. Carcinog. 54, 1480-1493. doi:10.1002/mc.22225

Sledge, G. W., Jr., Loehrer, P. J., Sr., Roth, B. J., and Einhorn, L. H. (1988). Cisplatin as first-line therapy for metastatic breast cancer. J. Clin. Oncol. 6, 1811-1814. doi:10.1200/JCO.1988.6.12.1811

Smalley, M., Piggott, L., and Clarkson, R. (2013). Breast cancer stem cells: obstacles to therapy. Cancer Lett. 338, 57-62. doi:10.1016/j.canlet.2012.04.023

Solzak, J. P., Atale, R. V., Hancock, B. A., Sinn, A. L., Pollok, K. E., Jones, D. R., et al. (2017). Dual PI3K and Wnt pathway inhibition is a synergistic combination against triple negative breast cancer. NPJ Breast Cancer 3, 17. doi:10.1038/ s41523-017-0016-8

Sridharan, S., Howard, C. M., Tilley, A. M. C., Subramaniyan, B., Tiwari, A. K., Ruch, R. J., et al. (2019). Novel and alternative targets against breast cancer stemness to combat chemoresistance. Front. Oncol. 9, 1003. doi:10.3389/fonc. 2019.01003

Strosberg, J. R., Yeatman, T., Weber, J., Coppola, D., Schell, M. J., Han, G., et al. (2012). A phase II study of RO4929097 in metastatic colorectal cancer. Eur. J. Cancer 48, 997-1003. doi:10.1016/j.ejca.2012.02.056

Sun, M., Yang, C., Zheng, J., Wang, M., Chen, M., Le, D. Q. S., et al. (2015). Enhanced efficacy of chemotherapy for breast cancer stem cells by simultaneous suppression of multidrug resistance and antiapoptotic cellular defense. Acta Biomater. 28, 171-182. doi:10.1016/j.actbio.2015.09.029

Sun, M., Zhang, N., Wang, X., Li, Y., Qi, W., Zhang, H., et al. (2016). Hedgehog pathway is involved in nitidine chloride induced inhibition of epithelialmesenchymal transition and cancer stem cells-like properties in breast cancer cells. Cell Biosci. 6, 44. doi:10.1186/s13578-016-0104-8

Sun, W. L., Chen, J., Wang, Y. P., and Zheng, H. (2011). Autophagy protects breast cancer cells from epirubicin-induced apoptosis and facilitates epirubicinresistance development. Autophagy 7, 1035-1044. doi:10.4161/auto.7.9.16521

Suman, S., Das, T. P., and Damodaran, C. (2013). Silencing NOTCH signaling causes growth arrest in both breast cancer stem cells and breast cancer cells. $B r$. J. Cancer 109, 2587-2596. doi:10.1038/bjc.2013.642

Swaminathan, S. K., Roger, E., Toti, U., Niu, L., Ohlfest, J. R., and Panyam, J. (2013). CD133-targeted paclitaxel delivery inhibits local tumor recurrence in a mouse model of breast cancer. J. Contr. Release 171, 280-287. doi:10.1016/j.jconrel. 2013.07.014

Takagi, K., Miki, Y., Nagasaki, S., Hirakawa, H., Onodera, Y., Akahira, J., et al. (2010). Increased intratumoral androgens in human breast carcinoma following aromatase inhibitor exemestane treatment. Endocr. Relat. Cancer 17, 415-430. doi:10.1677/ERC-09-0257

Tanei, T., Morimoto, K., Shimazu, K., Kim, S. J., Tanji, Y., Taguchi, T., et al. (2009). Association of breast cancer stem cells identified by aldehyde dehydrogenase 1 expression with resistance to sequential Paclitaxel and epirubicin-based chemotherapy for breast cancers. Clin. Cancer Res. 15, 4234-4241. doi:10. 1158/1078-0432.CCR-08-1479

Uchiumi, K., Tsuboi, K., Sato, N., Ito, T., Hirakawa, H., Niwa, T., et al. (2019). Cancer stem-like properties of hormonal therapy-resistant breast cancer cells. Breast Cancer 26, 459-470. doi:10.1007/s12282-018-00944-1

Valenti, G., Quinn, H. M., Heynen, G. J. J. E., Lan, L., Holland, J. D., Vogel, R., et al. (2017). Cancer stem cells regulate cancer-associated fibroblasts via activation of hedgehog signaling in mammary gland tumors. Cancer Res. 77, 2134-2147. doi:10.1158/0008-5472.CAN-15-3490

van't Veer, L. J., Dai, H., van de Vijver, M. J., He, Y. D., Hart, A. A., Mao, M., et al. (2002). Gene expression profiling predicts clinical outcome of breast cancer. Nature 415, 530-536. doi:10.1038/415530a

Vahidi, H., Barabadi, H., and Saravanan, M. (2020). Emerging selenium nanoparticles to combat cancer: a systematic review. J. Cluster Sci. 31, 301-309. 10.1007/s10876-019-01671-z

Vazquez-Martin, A., Cufi, S., Lopez-Bonet, E., Corominas-Faja, B., Cuyas, E., Vellon, L., et al. (2013). Reprogramming of non-genomic estrogen signaling by 
the stemness factor SOX2 enhances the tumor-initiating capacity of breast cancer cells. Cell Cycle 12, 3471-3477. doi:10.4161/cc.26692

Venkatesh, V., Nataraj, R., Thangaraj, G. S., Karthikeyan, M., Gnanasekaran, A., Kaginelli, S. B., et al. (2018). Targeting Notch signalling pathway of cancer stem cells. Stem Cell Invest. 5, 5. doi:10.21037/sci.2018.02.02

Vera-Ramirez, L., Vodnala, S. K., Nini, R., Hunter, K. W., and Green, J. E. (2018). Autophagy promotes the survival of dormant breast cancer cells and metastatic tumour recurrence. Nat. Commun. 9, 1944. doi:10.1038/s41467-018-04070-6

Versini, A., Colombeau, L., Hienzsch, A., Gaillet, C., Retailleau, P., Debieu, S., et al. (2020). Salinomycin derivatives kill breast cancer stem cells via lysosomal iron targeting.Chemistry 26, 7416-7424. doi:10.1002/chem.202000335

Virmani, I., Sasi, C., Priyadarshini, E., Kumar, R., and Meena, R. (2019). Comparative anticancer potential of biologically and chemically synthesized gold nanoparticles. J. Cluster Sci. 31, 1-10. doi:10.1007/s10876-019-01695-5

Wang, A., Qu, L., and Wang, L. (2017). At the crossroads of cancer stem cells and targeted therapy resistance. Cancer Lett. 385, 87-96. doi:10.1016/j.canlet.2016. 10.039

Wang, D., Xu, J., Liu, B., He, X., Zhou, L., Hu, X., et al. (2018). IL6 blockade potentiates the anti-tumor effects of $\gamma$-secretase inhibitors in Notch3expressing breast cancer. Cell Death Differ. 25, 330-339. doi:10.1038/cdd. 2017.162

Wang, R., Yang, L., Li, S., Ye, D., Yang, L., Liu, Q., et al. (2018). Quercetin inhibits breast cancer stem cells via downregulation of aldehyde dehydrogenase $1 \mathrm{~A} 1$ (ALDH1A1), chemokine receptor type 4 (CXCR4), Mucin 1 (MUC1), and epithelial cell adhesion molecule (EpCAM). Med. Sci. Mon. Int. Med. J. Exp. Clin. Res. 24, 412-420. doi:10.12659/msm.908022

Wang, T., Fahrmann, J. F., Lee, H., Li, Y. J., Tripathi, S. C., Yue, C., et al. (2018). JAK/STAT3-Regulated fatty acid $\beta$-oxidation is critical for breast cancer stem cell self-renewal and chemoresistance. Cell Metabol. 27, 136-150.e5. doi:10. 1016/j.cmet.2017.11.001

Wang, J., Gildea, J. J., and Yue, W. (2013). Aromatase overexpression induces malignant changes in estrogen receptor alpha negative MCF-10A cells. Oncogene 32, 5233-5240. doi:10.1038/onc.2012.558

Wang, L., Tian, H., Yuan, J., Wu, H., Wu, J., and Zhu, X. (2015). CONSORT: Sam68 is directly regulated by MiR-204 and promotes the self-renewal potential of breast cancer cells by activating the wnt/beta-catenin signaling pathway. Medicine 94, e2228. doi:10.1097/MD.0000000000002228

Wang, T., Gantier, M. P., Xiang, D., Bean, A. G., Bruce, M., Zhou, S. F., et al. (2015). EpCAM aptamer-mediated Survivin silencing sensitized cancer stem cells to doxorubicin in a breast cancer model. Theranostics 5, 1456-1472. doi:10.7150/ thno. 11692

Wang, X., Wang, G., Zhao, Y., Liu, X., Ding, Q., Shi, J., et al. (2012). STAT3 mediates resistance of $\mathrm{CD} 44(+) \mathrm{CD} 24(-/$ low $)$ breast cancer stem cells to tamoxifen in vitro. J. Biomed. Res. 26, 325-335. doi:10.7555/JBR.26.20110050

Wijdeven, R. H., Pang, B., van der Zanden, S. Y., Qiao, X., Blomen, V., Hoogstraat, M., et al. (2015). Genome-Wide identification and characterization of novel factors conferring resistance to topoisomerase II poisons in cancer, Cancer Res. 75, 4176-4187. doi:10.1158/0008-5472.CAN-15-0380

Wright, M. H., Calcagno, A. M., Salcido, C. D., Carlson, M. D., Ambudkar, S. V., and Varticovski, L. (2008). Brcal breast tumors contain distinct CD44+/CD24and CD133+ cells with cancer stem cell characteristics. Breast Cancer Res. 10, R10. doi:10.1186/bcr1855

Wu, D., Si, M., Xue, H. Y., and Wong, H. L. (2017). Nanomedicine applications in the treatment of breast cancer: current state of the art. Int. J. Nanomed. 12, 5879-5892. doi:10.2147/IJN.S123437

Wu, Y., Ginther, C., Kim, J., Mosher, N., Chung, S., Slamon, D., et al. (2012). Expression of Wnt3 activates Wnt/beta-catenin pathway and promotes EMTlike phenotype in trastuzumab-resistant HER2-overexpressing breast cancer cells. Mol. Cancer Res. 10, 1597-1606. doi:10.1158/1541-7786.MCR-12-0155-T

Xiao, Y., Humphries, B., Yang, C., and Wang, Z. (2019). MiR-205 dysregulations in breast cancer: the complexity and opportunities. Noncoding RNA 5, 53. doi:10. 3390/ncrna5040053

Xu, H., Zhou, Y., Li, W., Zhang, B., Zhang, H., Zhao, S., et al. (2018). Tumorderived mesenchymal-stem-cell-secreted IL- 6 enhances resistance to cisplatin via the STAT3 pathway in breast cancer. Oncol. Lett. 15, 9142-9150. doi:10. 3892/ol.2018.8463

Yang, L., Tian, Y., Leong, W. S., Song, H., Yang, W., Wang, M., et al. (2018). Efficient and tumor-specific knockdown of MTDH gene attenuates paclitaxel resistance of breast cancer cells both in vivo and in vitro. Breast Cancer Res. 20, 113. doi:10.1186/s13058-018-1042-7

Yang, Y., Hao, E., Pan, X., Tan, D., Du, Z., Xie, J., et al. (2019). Gomisin M2 from Baizuan suppresses breast cancer stem cell proliferation in a zebrafish xenograft model. Aging 11, 8347-8361. 10.18632/aging.102323.

Yang, Z., Guo, F., Albers, A. E., Sehouli, J., and Kaufmann, A. M. (2019). Disulfiram modulates ROS accumulation and overcomes synergistically cisplatin resistance in breast cancer cell lines. Biomed. Pharmacother. 113, 108727. doi:10.1016/j. biopha.2019.108727

Yi, T., Zhai, B., Yu, Y., Kiyotsugu, Y., Raschle, T., Etzkorn, M., et al. (2014). Quantitative phosphoproteomic analysis reveals system-wide signaling pathways downstream of SDF-1/CXCR4 in breast cancer stem cells. Proc. Natl. Acad. Sci. U.S.A. 111, E2182-E2190. doi:10.1073/pnas.1404943111

Yin, Y., Xie, C. M., Li, H., Tan, M., Chen, G., Schiff, R., et al. (2019). The FBXW2MSX2-SOX2 axis regulates stem cell property and drug resistance of cancer cells. Proc. Natl. Acad. Sci. U.S.A. 116, 20528-20538. doi:10.1073/pnas. 1905973116

Yoshida, G. J., and Saya, H. (2016). Therapeutic strategies targeting cancer stem cells. Cancer Sci. 107, 5-11. doi:10.1111/cas.12817

Yousaf, M., and Ali, M. (2020). Modulation of ABCG2 surface expression by Rab5 and Rab21 to overcome multidrug resistance in cancer cells. Xenobiotica 50, 1-9. doi:10.1080/00498254.2020.1716107

Yun, J., Pannuti, A., Espinoza, I., Zhu, H., Hicks, C., Zhu, X., et al. (2013). Crosstalk between PKCalpha and Notch-4 in endocrine-resistant breast cancer cells. Oncogenesis 2, e60. doi:10.1038/oncsis.2013.26

Zavala, V. A., Serrano-Gomez, S. J., Dutil, J., and Fejerman, L. (2019). Genetic epidemiology of breast cancer in Latin America. Genes 10, 153. doi:10.3390/ genes 10020153

Zhang, C. C., Pavlicek, A., Zhang, Q., Lira, M. E., Painter, C. L., Yan, Z., et al. (2012). Biomarker and pharmacologic evaluation of the gamma-secretase inhibitor PF-03084014 in breast cancer models, Clin. Cancer Res. 18, 5008-5019. doi:10.1158/1078-0432.CCR-12-1379

Zhang, Y., Eades, G., Yao, Y., Li, Q., and Zhou, Q. (2012). Estrogen receptor a signaling regulates breast tumor-initiating cells by down-regulating miR-140 which targets the transcription factor SOX2. J. Biol. Chem. 287, 41514-41522. doi:10.1074/jbc.M112.404871

Zhang, W., and Grivennikov, S. I. (2013). Top Notch cancer stem cells by paracrine NF-kappaB signaling in breast cancer, Breast Cancer Res. 15, 316. doi:10.1186/ bcr3565

Zhang, X., and Wang, Z. Y. (2013). Estrogen receptor- $\alpha$ variant, ER- $\alpha 36$, is involved in tamoxifen resistance and estrogen hypersensitivity, Endocrinology 154, 1990-1998. doi:10.1210/en.2013-1116

Zhao, D., Mo, Y., Li, M. T., Zou, S. W., Cheng, Z. L., Sun, Y. P., et al. (2014). NOTCH-induced aldehyde dehydrogenase $1 \mathrm{~A} 1$ deacetylation promotes breast cancer stem cells. J. Clin. Invest. 124, 5453-5465. doi:10.1172/JCI76611

Zhong, G., Qin, S., Townsend, D., Schulte, B. A., Tew, K. D., and Wang, G. Y. (2019). Oxidative stress induces senescence in breast cancer stem cells. Biochem. Biophys. Res. Commun. 514, 1204-1209. doi:10.1016/j.bbrc.2019.05.098

Conflict of Interest: The authors declare that the research was conducted in the absence of any commercial or financial relationships that could be construed as a potential conflict of interest.

Copyright $\odot 2021$ Zheng, Zhang, Zhou, Zhang and Meng. This is an open-access article distributed under the terms of the Creative Commons Attribution License (CC $B Y)$. The use, distribution or reproduction in other forums is permitted, provided the original author(s) and the copyright owner(s) are credited and that the original publication in this journal is cited, in accordance with accepted academic practice. No use, distribution or reproduction is permitted which does not comply with these terms. 